NBSIR 73-106 (R)

A System for Computerized Surface
Roughness Measurement

Dennis A. Swyt

Institute for Basic Standards National Bureau of Standards

Washington. D. C. 20234

February 20. 1973

Final Report

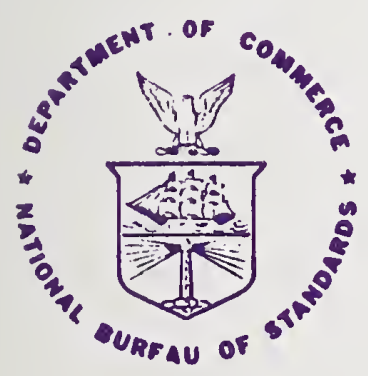

U. S. DEPARTMENT OF COMMERCE

NATIONAL BUREAU OF STANDARDS 

NBSIR 73-106

\section{A SYSTEM FOR COMPUTERIZED SURFACE ROUGHNESS MEASUREMENT}

Dennis A. Swyt

Institute for Basic Standards

National Bureau of Standards

Washington, D. C. 20234

February 20.1973

Final Report

U. S. DEPARTMENT OF COMMERCE, Frederick B. Dent, Secretary NATIONAL BUREAU OF STANDARDS, Richard W. Roberts. Director 

CONTENTS

Page

Introduction . . . . . . . . . . . . . . . . 1

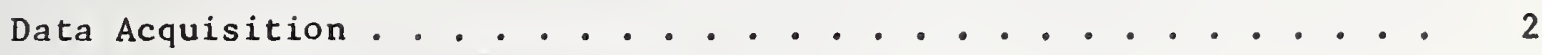

Data Analysis of Step Heights . . . . . . . . . . . 2

Data Analysis of Surface Roughnesses . . . . . . . . . . 3

Calibration of Step Heights and AA Values . . . . . . . . 3

Program Operations . . . . . . . . . . . . . . . 4

The AA Calculation and the ANSI Standard ........... 5

Noise Effect in AA Measurements . . . . . . . . . . 9

Partial Estimate of Accuracy . . . . . . . . . . . 10

Preliminary Results . . . . . . . . . . . . 12

Appendix A. The Linear Least Squares Curve Fit . . . . . . 18

Appendix B. Step Location . . . . . . . . . . . 20

Appendix C. The Mean Distance Between Two Non-Parallel Lines . . 22

Appendix D. Slope Scale Factor . . . . . . . . . . 25

Appendix E. Filter Characteristics . . . . . . . . . 27

Appendix F. Program Operation . . . . . . . . . . 28

Appendix G. Operator's Instructions: Interdata 3/Talysurf 4 System 34

Appendix H. Checklist for Proper Electrical Operation . . . . . 38 
. 


\section{ILLUSTRATIONS}

Page

Figure 1. Function Diagram of Talysurf/Interdata System . . . . 2a

Figure 2. Step Height Calculation ............ 2b

Figure 3. Teletype Output of Step/Surface Roughness Calibration . $4 a$

Figure 4. Noise Effect Measurement ........... 9a

Figure 5. Noise Effects in AA Readings .......... 10a

Figure 6. Uncertainties in AA Readings .......... 12a

Figure 7. Chart Paper/Memory Location Map . . . . . . . 20a

Figure 8. Proper Location of Step Relative to Event Marker . . 20b

Figure 9. Selection of $\mathrm{A}_{1}$ and $\mathrm{A}_{2}$ Locations ....... 20c

Figure 10. Proper and Improper Selection of $A_{1}$ and $A_{2}, \ldots . .21 a$

Figure 11. Vector Analysis of Step ............. 24a

Figure 12. Filter-Amplifier Gain-Bandpass Characteristics . . . 27a

Figure 13. Observed Amplifier-Filter Phase Delay ....... 27b

Figure 14. Internal Computer Lead Connections . . . . . . 34 a

Figure 15. Interface AC Power Connection . . . . . . . 34b

Figure 16. System Lead Connections . . . . . . . . . . 34c 

Table 1. Time Study of Measurement Procedure: Step ..... 6 Time Study of Measurement Procedure: Roughness . . . 7

Table 2. Contributions to Uncertainties in AA Readings . . . 13

Table 3. Uncertainties in AA readings for Different Magnifications . . . . . . . . . . . . 14

Table 4. Comparison of Results for NBS Master Roughness Block • 15

Table 5. Preliminary Measurements on NBS-1 Caliblock . . . 16

Table 6. Summary of Preliminary Results . . . . . . . 17

Table 7. Master Program Outline ............ 29

Table 8. Numerical Values in Sample Program Operation .... 31

Table 9. Characteristic Parameters of Entire System . . . . 32 

Dennis A. Swyt

\section{Introduction}

Prior to the development of the system to be described, the available basis for calibrations by NBS of roughness specimens for industrial consumers was by means of comparisons with a roughness master. The values assigned to the master involved single displacement calibrations of stylus instruments and hand calculations from planimeter measurements of surface profiles. The overall method has several limitations. Individual calibrations are referred to the historical values of roughness assigned to a unique artifact which is subject to loss, damage and deterioration with ordinary use. AA values, indicated on an integrating meter, are only accurate to $3 \%$ of full scale, cannot be displayed digitally, and must be subjectively interpolated between scale divisions. To eliminate these difficulties, a new system has been developed. At present, an Interdata 3 Minicomputer has been fully interfaced with a Talysurf 4 Stylus instrument. The completely operational system offers:

(1) instrument calibration at each use by means of interferometrically measured gage block steps;

(2) considerably more accurate AA values, computer-calculated for arbitrary specimens;

(3) computer-calculated thin film thicknesses;

(4) precise, digital print-out of measurement results in permanent record format;

(5) access to punched tape surface profile data which may be analyzed by a larger, faster computer to yield further information, e.g. peak height and roughness wavelength distributions.

Scheduled to be completed before the end of FY 1973 are:

(1) a complete determination of the dynamic operating characteristics of the entire system;

(2) the development of a range of interferometrically measured thin-film and gage-block steps;

(3) a changeover of surface roughness calibration setvices from those based on a roughness artifact to the new system;

(4) the introduction of thin-film thicknesses measurement services based in part on the computerized stylus instrument system. 


\section{Data Acquisition*}

The means by which topographical profiles are converted to surface roughness data is represented by the functional schematic in figure 1. When the stylus is traversed across a surface, the profile is indicated on the strip chart recorder; the signal driving the recorder, amplified and filtered, appears at the analog-to-digital converter (A/D).

At a particular point in the stroke, the stylus arm activates a relay, which in turn generates two pulses. The first pulse, one second long, appears at the common input of the recorder and interface amplifier. (The source of the event pulse is in the information channel only for the duration of the pulse). Coincident with the leading edge of the event pulse is a fifty-microsecond interrupt pulse to the $A / D$ converter. On receipt of the interrupt at the $A / D, a$ programmed one-second delay is executed, and the analog signal at the filter output is converted to binary data points and stored sequentially in computer memory. (Thus the event mark, recorded on the strip chart, does not appear in the digital data). The results of the computer analysis of the stored data are output to the Teletype, Model 33.

\section{Data Analysis of Step Heights}

In order to efficiently handle the discontinuity in the trace which comprises the step height and to eliminate restrictions on the alignment of the step artifact, a mathematical model of the step data in the computer memory has been devised. Figure 2 a represents a general step profile in which the traces on opposite sides of the discontinuity are wavy and parallel neither to each other nor to the sides of the strip chart.

Linear least-squares curves are fitted to the segments designated by $L 1$ and $\mathrm{L} 2$ in figure 2b (appendix A); the segments are located at

*ertain commercial equipment, instruments, or materials are identified in this paper in order to adequately specify the experimental procedure. In no case does such identification imply recommendation or endorsement by the National Bureau of Standards, nor does it imply that the material or equipment identified is necessarily the best available for the purpose. 


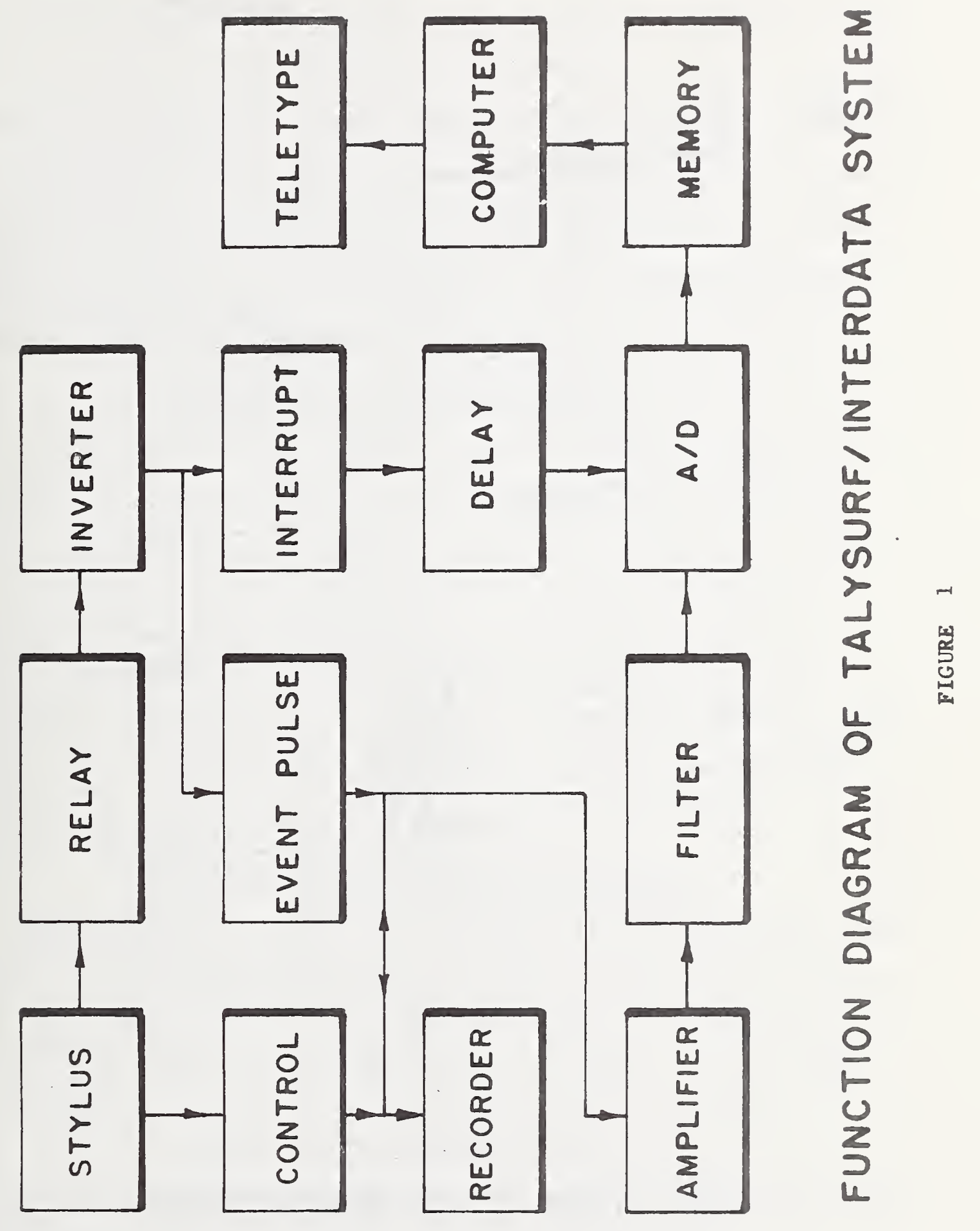


a)

$$
\ldots \ldots-\cdots-\cdots
$$

b)

c)

$$
\text { -. }
$$

d)

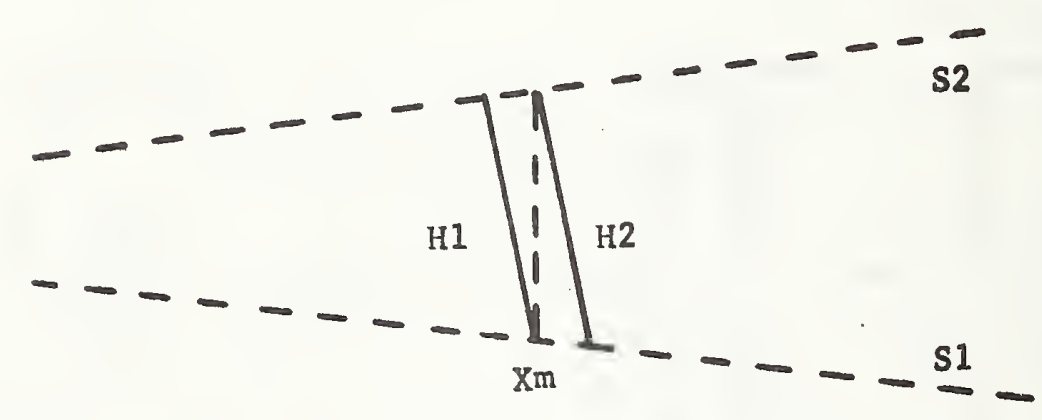

\section{)}

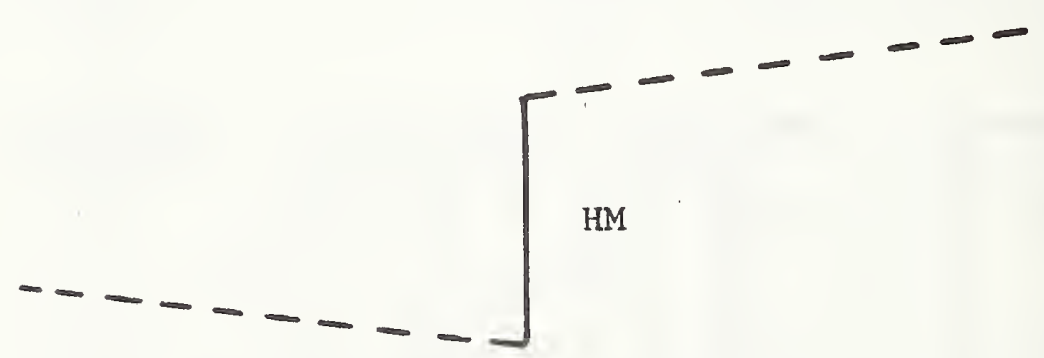

IIGURE 2 . STEP HEIGHT CALCULATION
a) Step Profile Input
b) Linear Least Squares Line Segments
c) Perpendicular Distances at $\mathrm{x}_{\mathrm{m}}$ between the Two Lines
d) Mean Distance of Step Helght 
the operator's discretion relative to the event mark (appendix B), are of equal lengths and constitute one-half of the total trace. From the slopes and intercepts of the two computed 1 ines, S1 and S2 in figure 2c, are calculated the distances $\mathrm{H} 1$ and $\mathrm{H} 2$ (appendices $\mathrm{C}$ and $\mathrm{D}$ ); the two heights are the perpendicular distances from the points on each line, having the coordinate $\mathrm{xm}$, to the opposite lines. The distance HM in figure $2 \mathrm{~d}$ is the arithmetic mean of $\mathrm{H} 1$ and $\mathrm{H} 2$.

\section{Data Analysis of Surface Roughnesses}

The AA roughness for a surface profile is computed from the data in memory in a manner analogous to the operation of an integrating meter. Since the profile signal has wavelength cut-off restrictions imposed by analog filtering (appendix E), no digital filtering or signal conditioning is involved. The value corresponding to the center line of the profile is the arithmetic average of all points in the record. The AA value is the arithmetic average of the magnitudes of the deviations of each point from the mean.

\section{Calibration of Step Heights and AA Values}

When the binary HM value of the calibration step profile has been computed and the decimal Ho value of the interferometrically measured calibration step entered at the Teletype, a conversion constant, KCAL, is computed:

$$
\mathrm{KCAL}=\mathrm{Ho}(\operatorname{decima} 1) / \mathrm{HM} \text { (binary). }
$$

The calibrated values of unknown steps and surface roughnesses are then of the form: 
HM (decimal) = HM (binary) $\times$ KCAL

and

$\mathrm{AA}($ decimal) $=\mathrm{AA}$ (binary) $\times \mathrm{KCAL}$.

\section{Program Operations}

An example of a calibration, wherein an unknown step and roughness are measured, may be illustrative. A sample Teletype output is given in figure 3. Further details appear in appendix F.

After an appropriate magnification has been selected, the corresponding gage block step is aligned on the Talysurf and program execution begun. At the proper point in the program, the operator is informed at the teletype to begin the stylus stroke in order to enter the calibration step profile. In this case, a 50 microinch step at 20,000 mangification produces a one-inch displacement on the chart and a one-volt output to the amplifier. The signal is amplified by 10, filtered (appendix E), converted to 512 twelve-bit data points over a 25 second record length and stored in memory. The operator is then instructed to enter $\mathrm{HO}$, the measured value of the gage block step, at the teletype; this four decimal-digit number is converted to binary and stored. The operator now enters the information at the teletype which locates the step discontinuity in the stored data; the information is derived from the chart trace and the step locator chart (appendix B).

The step height is computed, converted to decimal and printed; the printed calibration step height HM should conform with in tolerances 
ENTEK DATA/ IN ENTER HO 9014 ENIER UNITS TU ENTER AI IIRA ENTER AR I?.।4 H1 H2 HO UNITS

000090140000901400009014 TU MORE? Y H OR R? H

ENTER DATA/ IN ENTER HO ENTER UNITS TU ENTER AI 118 A ENTER A2 1214 HI H2 HO UNITS

000089930000899300008993 TU MORE? Y H OR R? H

ENTER DATA/ IN ENTER HO ENTER UNITS TU ENTER AI 113 A ENTER A2 1214 HI H2 HO UNITS

000089980000899800008998 TU MORE? Y H OR R? H

ENTER DATA/ IN ENTER HO ENTER UNITS TU ENTER AI 118 A ENTER A2 1214 HI H2 HO UNITS

000090150000901500009015 TU MORE? Y H OR R? H

ENTEK DATA/ IN ENTER HO ENTER UNITS TU ENTER AI 118 A ENTER A2 1214 HI H2 HO UNITS

000090090000900900009009 TU MORE? Y H OR R? H

ENTER DATA/ IN ENTER HO ENTER UNITS TU ENTER AI 11 BA ENTER A2 1214 HI H2 HO UNITS

000090130000901300009013 TU

$A A$

$00001214 \mathrm{TU}$

00001217

00001213

00001205

00001211

00001202

$A A$

00001204 00001208 00001210 00001213 00001206 00001208

$A A$

00001202 00001205 00001199 00001201 00001204 00001209

AA

$00001212 \mathrm{TU}$

00001201

00001210

00001208

00001207

00001204

TU
UNITS

MORE? Y H OR R? R ENTER DATA/ IN

MORE? Y H OR R? R ENTER DATA/ IN

UNITS

TU

UNITS

MORE? $Y$ H OR R? R ENTER DATA/ IN

MORE? N FIN I

FIGURE 3

$4 a$ 

the HO previously entered.

The operator now aligns the specimen to be measured on the stylus instrument. On being queried at the Teletype, the operator indicates the type of artifact. If it is a step, an $\mathrm{H}$ is entered and the procedure for entering a step profile repeated. If a roughness is to be measured, the proper filter cut-off and stroke speeds are selected, an $\mathrm{R}$ entered at the teletype and the stroke begun. The computer calculates either a step height or roughness $A A$, prints the result, and asks if more measurements are to be made from the same calibration. If more are to be made, a $\mathrm{Y}$ is entered at the teletype and the measurement of the unknown as described in this paragraph repeated. If no more measurements or those at a different magnification are to be made, an $\mathrm{N}$ is entered and the program is terminated.

A rough timetable for the program operation is given in table 1 . The AA Calculation and the ANSI Standard

The AA roughness value of a surface profile is defined as the arithmetic average deviation from the center line; the center line in turn is defined by the ANSI B46.1 standard as "the line parallel to the general direction of the profile within the limits of the roughness width cut-off, such that the sums of the areas contained between it and those parts which lie on either side of it are equal". The specific details involved in the implementation of these definitions in the operation of analog or digital devices are not delineated in the standard. While band-pass characteristics in 
Operator Function:

Align Calibration Artifact; Begin Program (5 min.)

Select A1 and A2 from Chart \& Scale, enter ( 1 min.)

Align Unknown Step

(5 min.)

Select A1 \& A2 from Chart \& Scale, enter ( 1 min.)

Operator Function Time

(12 min.)
Machine Function:

Input Step Data (0.5 min.)

Compute Step Height

$(0.25)$ min.)

Input Step Data

$(0.5$ min.)

Compute Unknown; Exit $(0.25 \mathrm{~min}$.

Machine Function Time $(1.5 \mathrm{~min}$.

Total Time

$13.5 \mathrm{~min}$.

Table 1 
Operator Function

Align Calibration Artifact; Begin Program (5 min.)

Select $\mathrm{A} 1$ and $\mathrm{A} 2$ from Chart \& Scale; Enter (1 min.)

\section{A1ign Unknown Roughness} (5 min.)

Operator Function Time

$(11 \min )$
Machine Function

Input Step Data

$(0.5$ min.)

Compute Step Height (0.25 min)

Input Roughness Data (0.05 min.)

Compute AA; Exit (0.25 min.)

Machine Function Time

( 1 min.)

Tota 1 Time

12 min. 
terms of half-power points and roll-off rates are specified, the exact nature of center-line, to which a profile is instantaneously referenced, is not clearly specified (again see appendix E for filter characteristics).

In the operation of an integrating-meter stylus instrument, the filtered signal represents the surface profile with wavelength cut-off restrictions imposed. The continuous analog computations of the center line and average deviation from the center line are made by integrating circuitry. Specifically, the stylus instrument stroke is begun and the resulting signal integrated to establish a center-line; at a particular point in the stroke, the instantaneous signal is compared to the established center line and the magnitude of the difference integrated for the remaining length of the stroke. Mathematically, the operation corresponds to the integral:

$$
A A=\frac{1}{T_{3}-T_{2}} \int_{T_{2}}^{T}\left[\text { Abs }\left(f(t)-\frac{1}{t-T_{1}} \int_{T_{1}}^{t} f\left(t^{\prime}\right) d t^{\prime}\right)\right] d t \text {. }
$$

This equation reflects the necessity in an analog device of comparing the instantaneous signal to a center line which does not bracket the signal, but rather represents a segment of the profile of which the signal is the trailing edge.

In the operation of the present digital system, the filtered signal is digitized and stored in the computer memory; the conversion rate $(1.64 \mathrm{kHZ})$ is sufficiently high to reproduce the analog 
information in the filter bandpass ( $f_{c}=300 \mathrm{HZ}$ ) with no loss of $\mathrm{fi}$ delity. The record length of the data corresponds to five wavelength cut -off widths. Since wavelength cut-off restrictions have been imposed on the signal by filtering, the center line is computed over the record length. Mathematically, the operation corresponds to the integra1:

$$
A A=\frac{1}{T} \int_{0}^{T}\left[\operatorname{Abs}\left(f(t)-\frac{1}{T} \int_{0}^{T} f\left(t^{\prime}\right) d t^{\prime}\right)\right] d t
$$

Although the mathematical descriptions of the analog and digital computations differ, it is believed that the digital computations are in accord with the present ANSI B46.1 surface texture standard, in terms of the fundamental definitions of $\mathrm{AA}$ and the center line. Since the effective center 1 ine is computed as the mean over the record length and the record width is five times the cut-off width, the effect of a fractional roughness wavelength in the record length is greatly diminished.

\section{Noise Effect in AA Measurements}

It is known that measurements of ultrafine finishes are limited in accuracy by the inherent noise level of the stylus instrument itself. The specific effect of this noise has been established by a study of the computer measured $\mathrm{AA}$ values as a function of the signalto-noise ratio. The experimental set-up is shown in figure 4. An operational amplifier was employed as an inverting adder without 


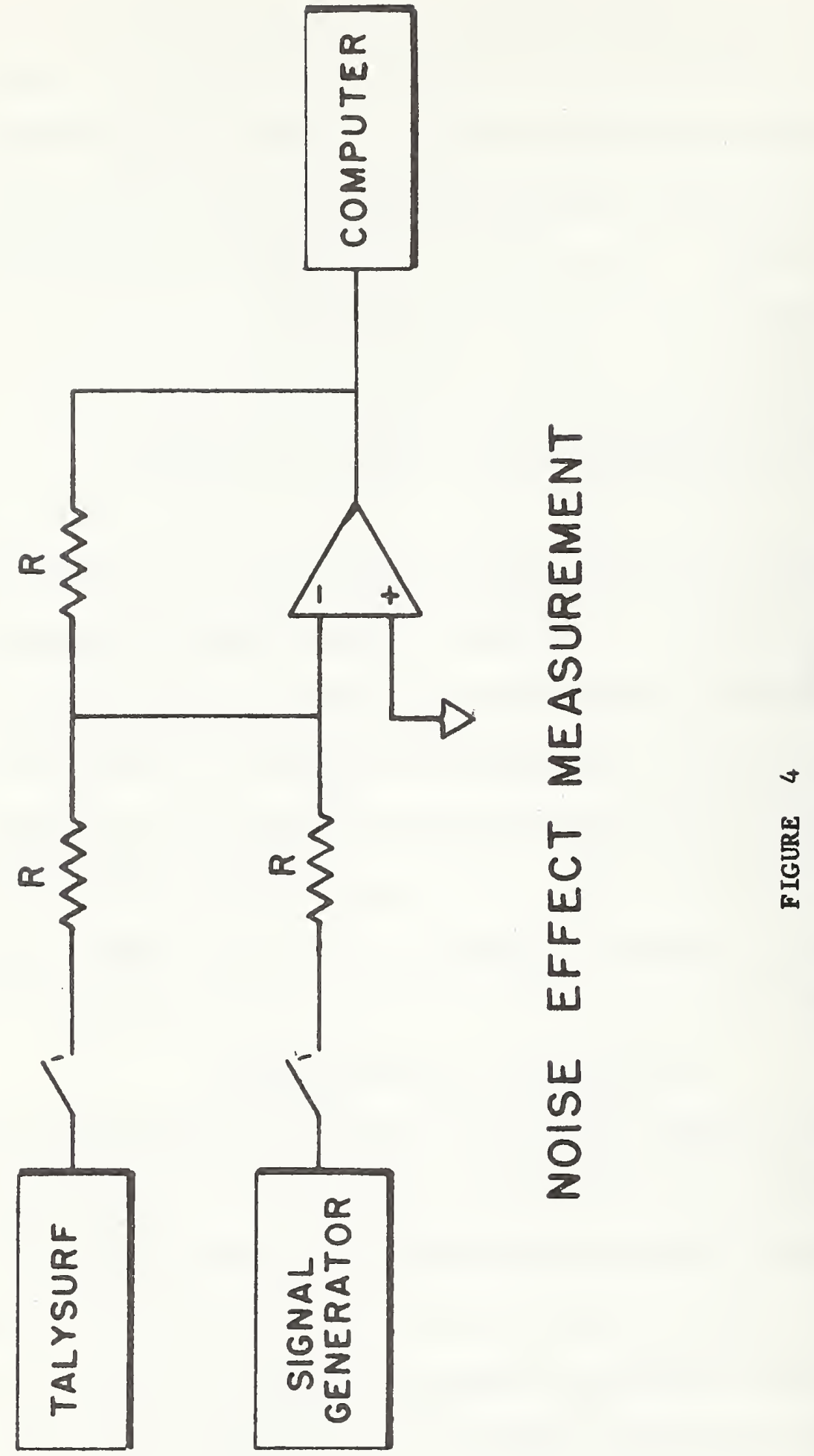




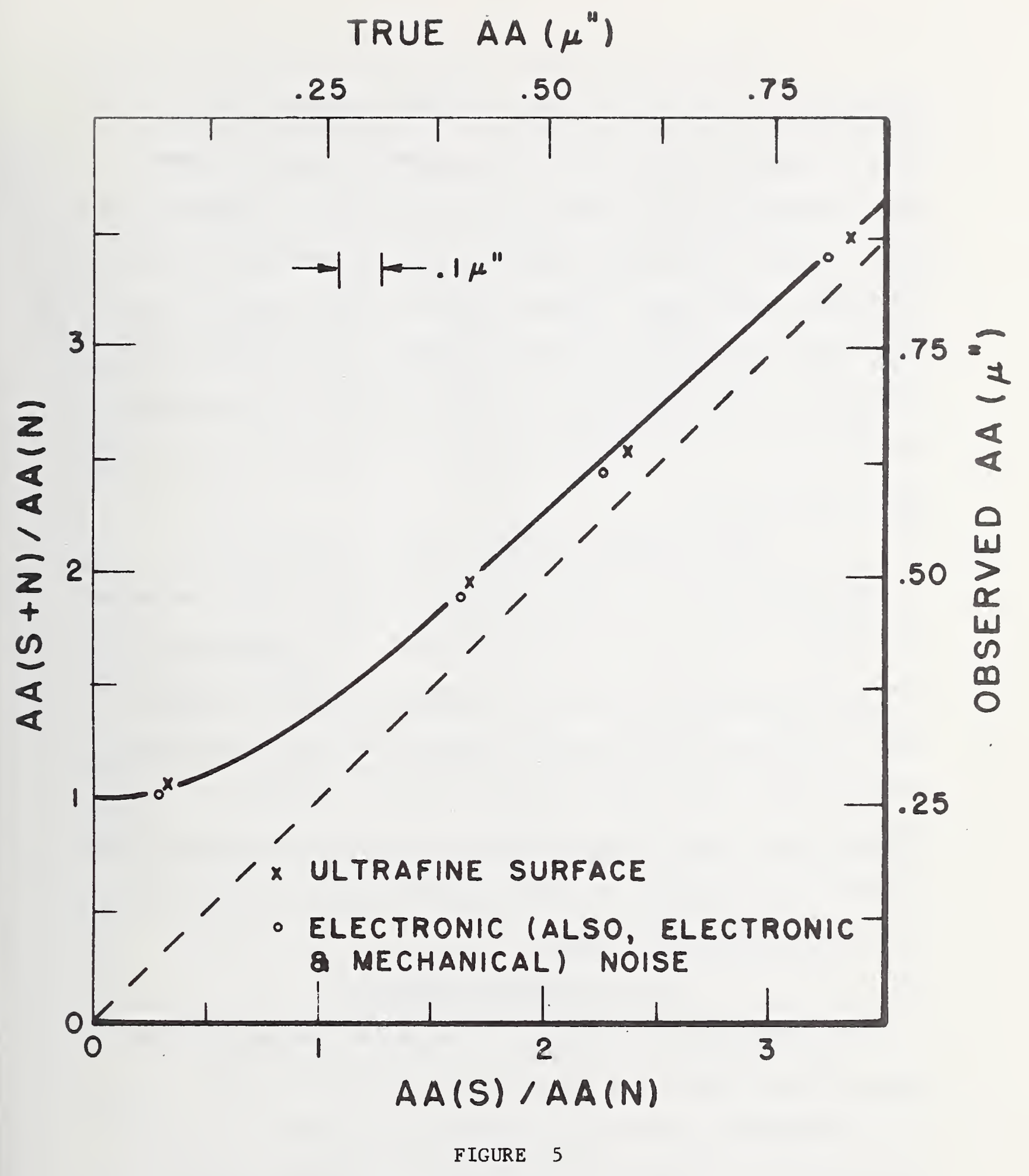


weighting. The apparatus allowed the stylus instrument output to be measured separately and combined with a measured signal. Measurements were made of the inherent electronic noise in the system (with the stylus stationary), the mechanical and electronic noise (stylus resting on a plane which traversed with the stylus), and the stylus output while traversing an ultrafine surface (a float-formed glass substrate). The results for each case, normalized to the zero signal input level, are indicated in figure 5. The smooth curve represents the equation:

$$
\text { Signal Output }=\left[(\text { Signal Input })^{2}+(\text { Noise })^{2}\right]^{1 / 2} \text {. }
$$

The actual "noise" levels associated with the three cases above indicated: (1) an electronic noise of $.13 \mu "$, (2) a mechanical and electronic noise of $.16 \mu^{\prime \prime}$ and (3) a probable minimum AA reading of $.25 \mu "$. It has not been determined what portion of the minimum AA reading is due to the highly polished surface. Therefore, it is assumed that the full minimum reading is due to the instrument; thus, the total inherent noise is taken to be $.25 \mu^{\prime \prime}$ and its effect on AA readings is also shown in figure 5 .

\section{Partial Estimate of Accuracy}

The elements which contribute to the overall accuracy of the roughness measurements are manifold; they include the accuracy of the interferometry measurement of the calibration step, the transfer characteristics of the stylus instrument and interface hardware, the computational precision of the software, the suitability of the 
mathematical models, and the noise levels in the system.

In table 2, the contributions of the operating characteristics of the interface hardware (amplifier, filter and A/D converter) are itemized; the total error in the signal due to the interface is estimated to be $.15 \%$. The uncertainty in the computation of the AA values due to the intermediate calculations of the calibration step height, calibration constant and AA values, is considered to be $.075 \%$. The sum of the effects of the interface and computation is, therefore, about $.25 \%$, as indicated by $\Delta$ (comp) in table 2 .

The uncertainty in the interferometric measurements of the gage block steps is \pm 1 microinch. The corresponding percentage uncertainties, $\triangle(\mathrm{cal})$, range from $5 \%$ to $.025 \%$ for the different magni fications involved.

Finally, a constant noise level of about .25 microinches contributes uncertainties at different magnifications ranging from 170 . to $0 \%$.

The effect on the observed AA values of incremental changes in the calibration, computation and noise levels appears as:

$$
\mathrm{AA}(\mathrm{obs})=(1+\Delta(\mathrm{cal}))(1+\Delta(\text { comp })) \sqrt{\mathrm{AA}(\text { true })^{2}+\mathrm{N}^{2}} \text {, }
$$

which leads to the first order uncertainty in the AA values given by:

$$
\triangle A A=A A[\mid \triangle(\text { cal })|+| \Delta(\text { comp })|+| \Delta(N)]
$$

where

$$
\left.\Delta \mathrm{N}=\left(1+\frac{\mathrm{N}}{\mathrm{AA}}\right)^{2}\right)^{1 / 2}-1
$$

The uncertainty of the AA measurements (exclusive of stylus- 
preamplifier response) as indicated in table 3 is shown in the graph of figure 6. The curve indicates accuracies for the standard 20 and 120 microinch patches of \pm .2 and \pm .4 microinches, respectively. These partial estimates of accuracy correspond to uncertainties of \pm 1.2 and \pm 12.0 for integrating meter readings of the stylus instrument and \pm 2.04 and \pm 0.93 for the round-robin determinations of the NBS master artifact; a comparison summary of these results appears in table 4.

\section{Preliminary Results}

Trial measurements of the round-robin calibrated artifact, designated NBS-1, have been made on the nominal 20 and 125 microinch patches. The roughnesses were measured at least four times at each of five different locations on each of the two masked regions of the patches. The results, including $3 \sigma$ values, are given in table 5. A general summary, including the estimate of accuracies of individual readings based on figure 6 and including the results of the round-robin calibration, appear in table 6 .

Some interesting effects are indicated in tables 5 and 6. First, the reproducibility of readings at individual scan locations is not significantly different than the reproducibility of readings for the masked regions of the patch; i.e.,

$$
3 \sigma(\operatorname{scan}) \approx 3 \sigma(\text { patch }) \text {. }
$$

This result may indicate an important contribution of stylus response to overall accuracy. Second, the results of the computer AA values and 


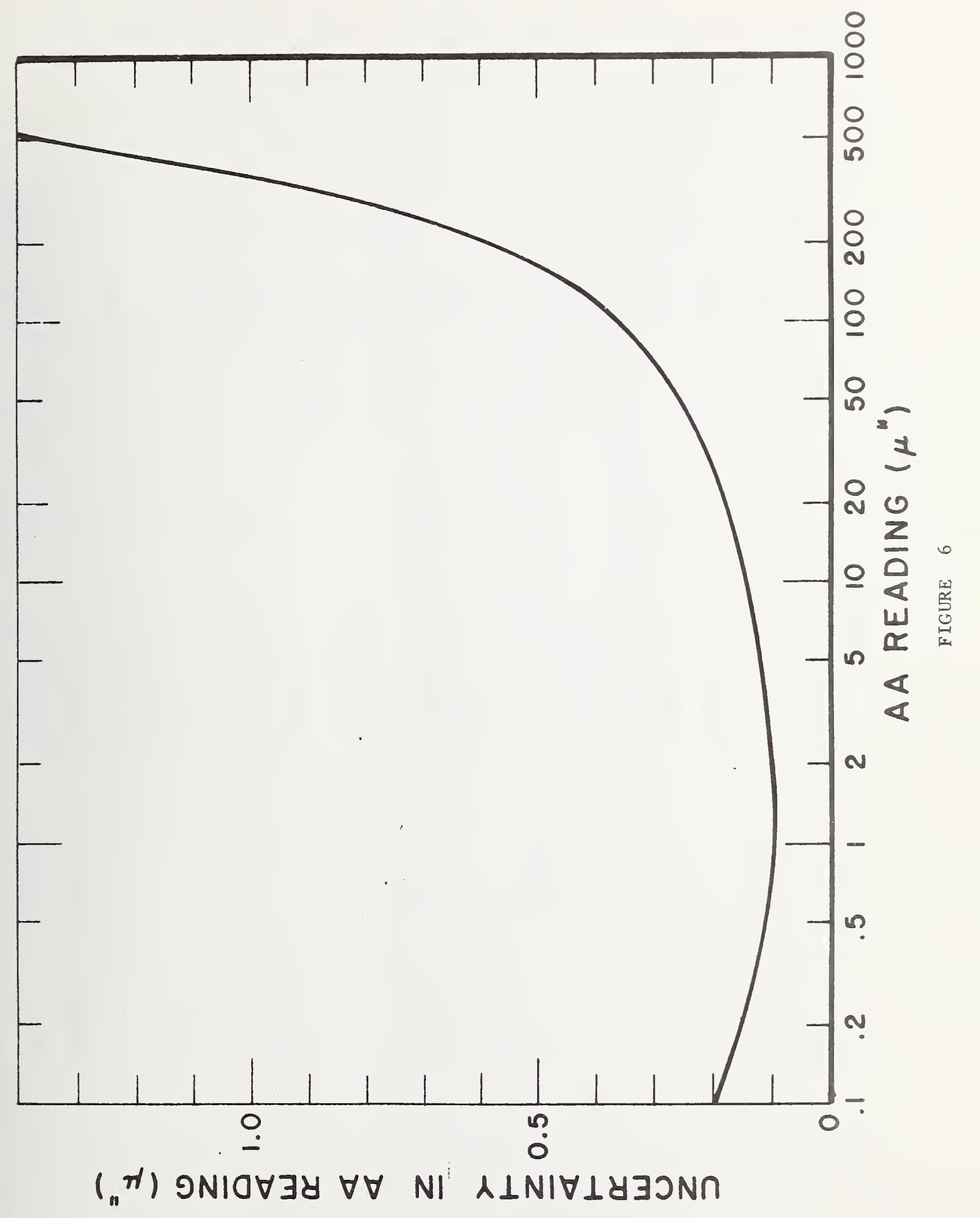





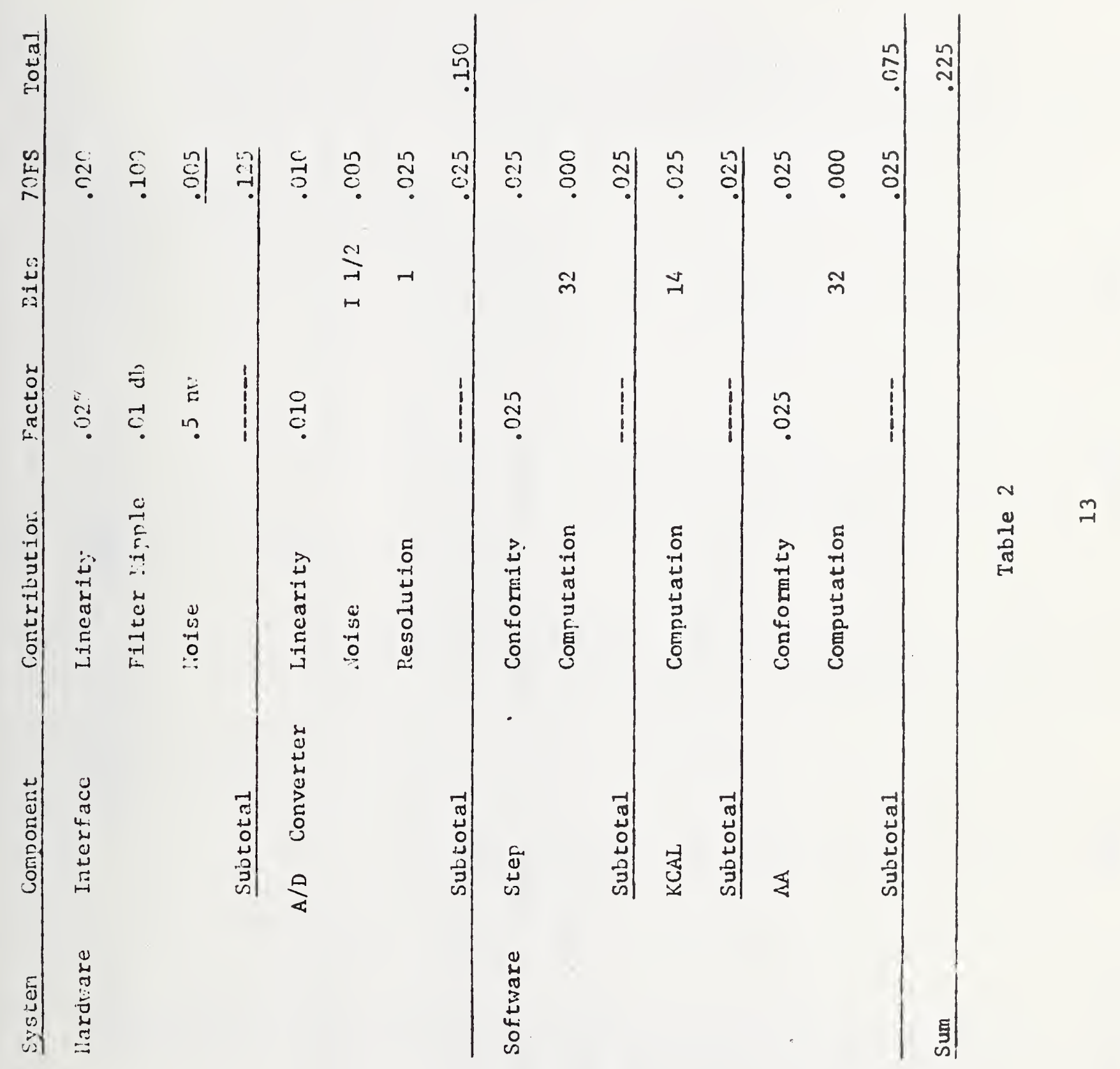




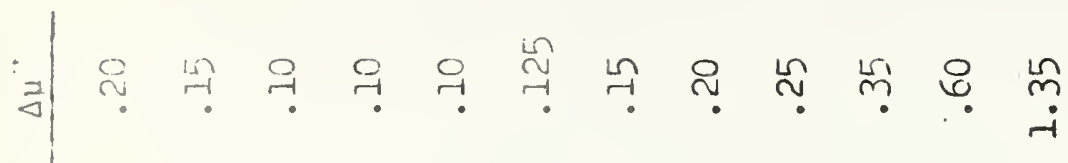

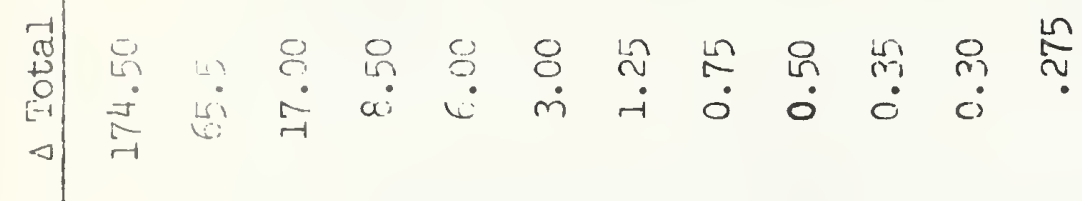

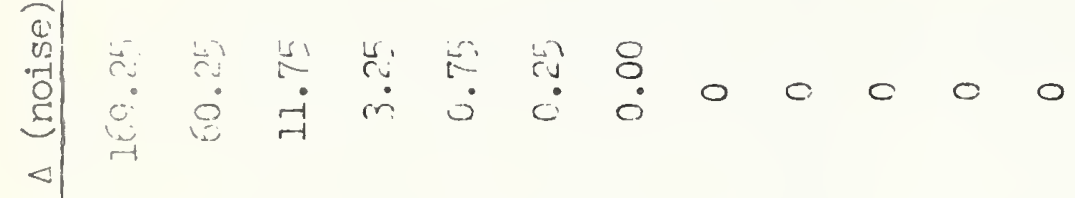

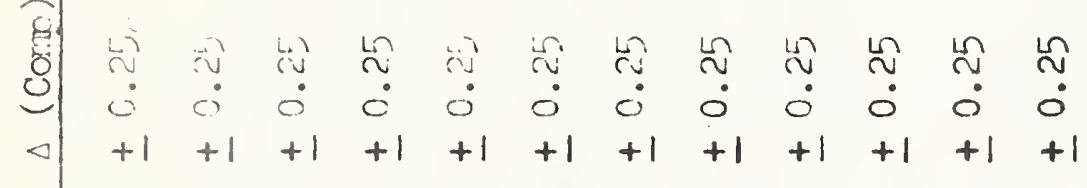

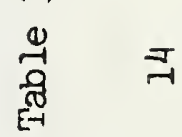

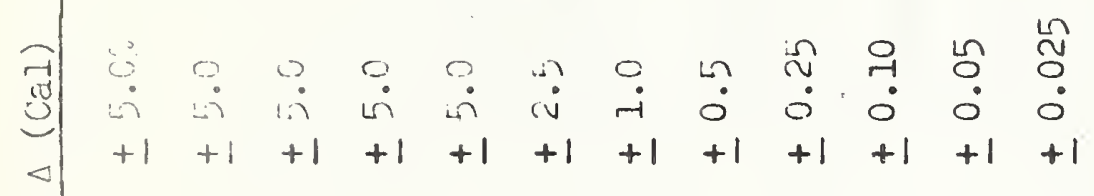

$\widetilde{3}$

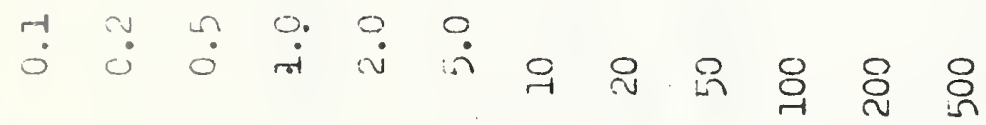

.

(4)

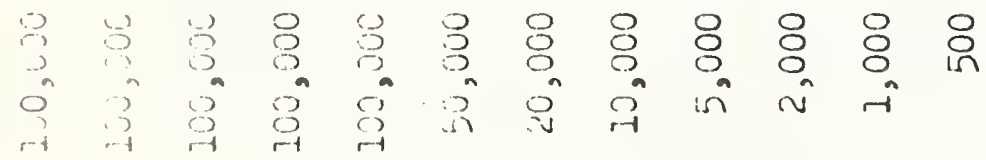




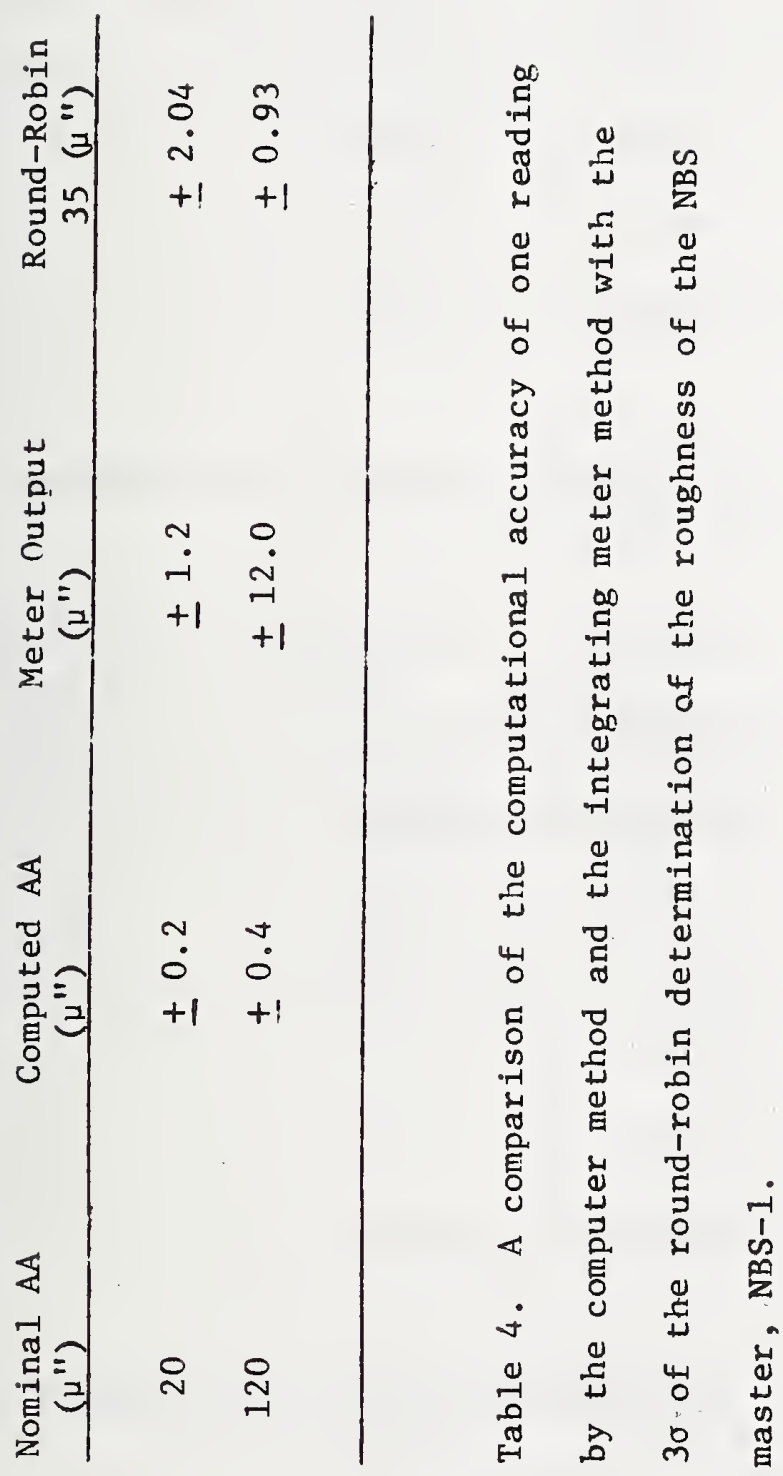


Table 5. Preliminary measurements on NBS-1 Caliblock.

Nominal 20 microinch patch

\begin{tabular}{ccc} 
Scan Location & $\mathrm{AA}\left(\mu^{\prime \prime}\right) *$ & $3 \sigma\left(\mu^{\prime \prime}\right)$ \\
\hline 1 & 20.74 & 0.24 \\
2 & 20.69 & 021 \\
3 & 20.87 & 0.24 \\
4 & 20.77 & 0.10 \\
5 & 20.90 & 0.15 \\
\hline
\end{tabular}

*Average of four readings with an estimated accuracy in each reading of $0.2 \mu^{\prime \prime}$ based on Figure 6.

Nominal 125 microinch patch

\begin{tabular}{ccc} 
Scan Location & $\mathrm{AA}\left(\mu^{\prime \prime}\right)^{t}$ & $3 \sigma\left(\mu^{\prime \prime}\right)$ \\
1 & 121.0 & 1.4 \\
2 & 121.1 & 1.2 \\
3 & 121.3 & 1.5 \\
4 & 121.6 & 1.2 \\
5 & 121.6 & 1.2 \\
\hline
\end{tabular}

${ }^{t}$ Average of five readings with an estimated accuracy in each reading of $0.4 \mu^{\prime \prime}$ based on Figure 6 . 
the round-robin values agree almost within the one $\sigma$ of either measurement; i.e.,

$$
(\mathrm{AA} \pm \sigma) \text { computer } \simeq(\mathrm{AA} \pm \sigma) \text { round-robin. }
$$

Further studies into the overall precision and accuracies of the computer calculated surface roughnesses are to be made and may reveal the bases for these results.

Table 6. Summary of Preliminary Results

\begin{tabular}{ccccccc}
\hline $\begin{array}{c}\text { Nominal } \\
\text { AA } \\
\left(\mu^{\prime \prime}\right)\end{array}$ & $\begin{array}{c}\text { Calibration } \\
\text { Step } \\
\left(\mu^{\prime \prime}\right)\end{array}$ & $\begin{array}{c}\text { Calibration } \\
\text { Check } \\
\left(\mu^{\prime \prime}\right)\end{array}$ & $\begin{array}{c}\text { Average } \\
\text { AA } \\
\left(\mu^{\prime \prime}\right)\end{array}$ & $\begin{array}{c}3 \sigma \\
\left(\mu^{\prime \prime}\right)\end{array}$ & $\begin{array}{c}\text { Round - } \\
\text { Robin } \\
\left(\mu^{\prime \prime}\right)\end{array}$ & $\begin{array}{c}3 \sigma \\
\left(\mu^{\prime \prime}\right)\end{array}$ \\
\hline 125 & $901.4 \pm 1.0$ & 901.5 & 121.3 & 1.5 & 120.76 & 2.04 \\
20 & $75.0 \pm 1.0$ & 74.4 & 20.79 & 0.3 & 20.34 & 0.93 \\
\hline
\end{tabular}




\section{The Linear Least Squares Curve Fit}

For the general case of a linear least squares (LSQ) curve fit of the form:

$$
y=a x+b,
$$

where $\mathrm{y}$ is the dependent variable, $\mathrm{x}$ the independent, a the slope, and b the intercept, the following formulae apply:

$$
\begin{aligned}
& b=\frac{1}{N} \sum y_{i}-\frac{a}{N} \sum x_{i} \\
& a=\frac{N \sum x_{i} y_{i}-\left(\sum x_{i}\right)\left(\sum y_{i}\right)}{N \sum x_{i}^{2}-\left(\sum x_{i}\right)^{2}}
\end{aligned}
$$

where $\Sigma$ indicates the $s$ umation over the $\mathrm{n}$ index from 1 to $\mathrm{N}$.

For the special case of equally spaced $x$ increments, $x_{i}$ may be replaced by an integer $n$ corresponding to the value of $i$ and the summations over $x_{i}$ and $x_{i}^{2}$ evaluated as standard series.

$$
\Sigma x_{i}=\Sigma n=\frac{N}{2}(N+1)
$$

$$
\sum x_{i}^{2}=\sum n^{2}=\frac{N}{6}(N+1)(2 N+1)
$$

Substitution of equations (3) and (4) into equations (1) and (2), with some simplification, leads to:

$$
b=\frac{1}{N} \sum y_{i}-\frac{a}{2}(N+1)
$$


(6) $\quad a=\frac{12 \sum n y_{i}-6(N+1) \sum y_{i}}{N(N+1)(N-1)}$

Where $\mathrm{N}$ is large, the denominator may be approximated by $\mathrm{N}^{3}$. (In the case of 128 data points, the subsequent error in the calculated slope is about $.005 \%$.) Thus,

(7) $\quad a=\frac{1}{N^{3}}\left[12 \sum n y_{n}-6(N+1) \sum y_{n}\right]$. 


\section{Step Location}

At the interrupt signal generated at the appropriate position in the stylus stroke, a one second delay is executed by the computer and data is read into memory for twenty-five seconds at the rate of approximately twenty points per second. Since the event marker is in the information channel, the delay is necessary to avoid reading the event marker as data. The signal which is recorded in those twenty-five seconds is thus entered as 512 data points in memory locations ${ }^{1000}{ }_{16}$ to $1_{1400}{ }^{\circ}$ The memory locations of selected points and the corresponding positions on the strip chart (measured in mm relative to the trailing edge of the event marker as in figure 7) are indicated in figure 8.

Figure 8 a represents a properly positioned step, approximately centered within the $40 \mathrm{~mm}-110 \mathrm{~mm}$ region. A representation of the data recorded im memory is given in figure $8 \mathrm{~b}$.

The length of the segment on the chart, corresponding to the 128 points over which a least-squares straight line is computed, is $37.5 \mathrm{~mm}$. The address $\mathrm{A}_{1}$ (input during program execution) must correspond to a location in the region $40 \mathrm{~mm}$ to the step edge; similarly, $\mathrm{A}_{2}$ must correspond to a location in the region between the step edge and the 110 mm position (see figure 9a). The line segments corresponding to the $A_{1}$ and $A_{2}$ selected are indicated in figure 9b. Choices for $A_{1}$ and $\mathrm{A}_{2}$ are limited to pairs of points situated equally distant to the left 


\begin{tabular}{|c|c|c|c|}
\hline 0040 & 1116 & 0075 & 1206 \\
\hline 0041 & $111 \mathrm{E}$ & 0076 & $120 E$ \\
\hline 0042 & 1124 & 0077 & 1214 \\
\hline 0043 & $112 \mathrm{~A}$ & 0078 & $121 \mathrm{~A}$ \\
\hline 0044 & 1132 & 0079 & 1222 \\
\hline 0045 & 1138 & 0080 & 1228 \\
\hline 0046 & 1140 & 0081 & 1230 \\
\hline 004.7 & 1146 & 0082 & 1236 \\
\hline 0048 & $114 E$ & 0083 & $123 E$ \\
\hline 0049 & 1154 & 0084 & 1244 \\
\hline 0050 & 115A & 0085 & $124 \mathrm{~A}$ \\
\hline 0051 & 1162 & 0086 & 1252 \\
\hline 0052 & 1168 & 0087 & 1258 \\
\hline 0053 & 1170 & 0088 & 1260 \\
\hline 0054 & 1176 & 0089 & 1266 \\
\hline 0055 & $117 \mathrm{E}$ & 0090 & $126 E$ \\
\hline 0056 & 1184 & 0091 & 1274 \\
\hline 0057 & $118 \mathrm{~A}$ & 0092 & $127 A$ \\
\hline 0058 & 1192 & 0093 & 1282 \\
\hline 0059 & 1198 & 0094 & 1288 \\
\hline 0060 & $11 \mathrm{AO}$ & 0095 & 1290 \\
\hline 0061 & $11 \mathrm{~A} 6$ & 0096 & 1296 \\
\hline 0062 & $11 \mathrm{AE}$ & 0097 & $129 E$ \\
\hline 0063 & $11 B 4$ & 0098 & $12 \mathrm{~A} 4$ \\
\hline 0064 & $11 B A$ & 0099 & 12AA \\
\hline 0065 & $11 \mathrm{C} 2$ & 0100 & $12 B 2$ \\
\hline 0066 & $11 C 8$ & 0101 & $12 B 8$ \\
\hline 0067 & $11 D 0$ & 0102 & $12 \mathrm{CO}$ \\
\hline 0068 & 11D6 & 0103 & $12 \mathrm{C} 6$ \\
\hline 0069 & 11DE & 0104 & $12 \mathrm{CE}$ \\
\hline 0070 & $11 E 4$ & 0105 & $12 \mathrm{D} 4$ \\
\hline 0071 & 11EA & 0106 & $12 D A$ \\
\hline 0072 & $11 F 2$ & 0107 & $12 \mathrm{E} 2$ \\
\hline 0073 & $11 F 8$ & 0108 & $12 \mathrm{E} 8$ \\
\hline 0074 & 1200 & 0109 & $12 F 0$ \\
\hline
\end{tabular}

FIGURE 7 


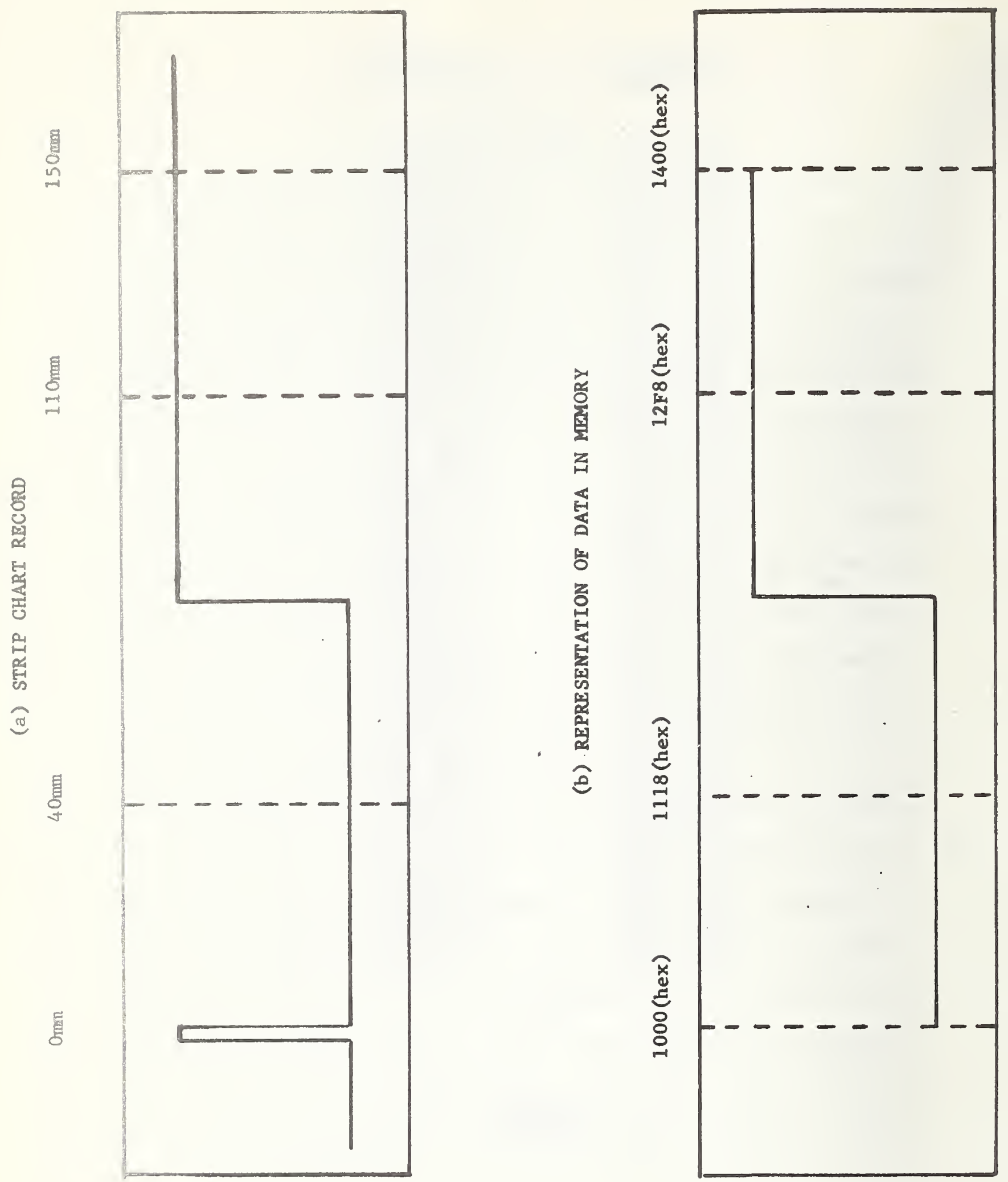

FIGURE 8. PROPER LOCATION OF STEP RELATIVE TO EVENT MARKER 


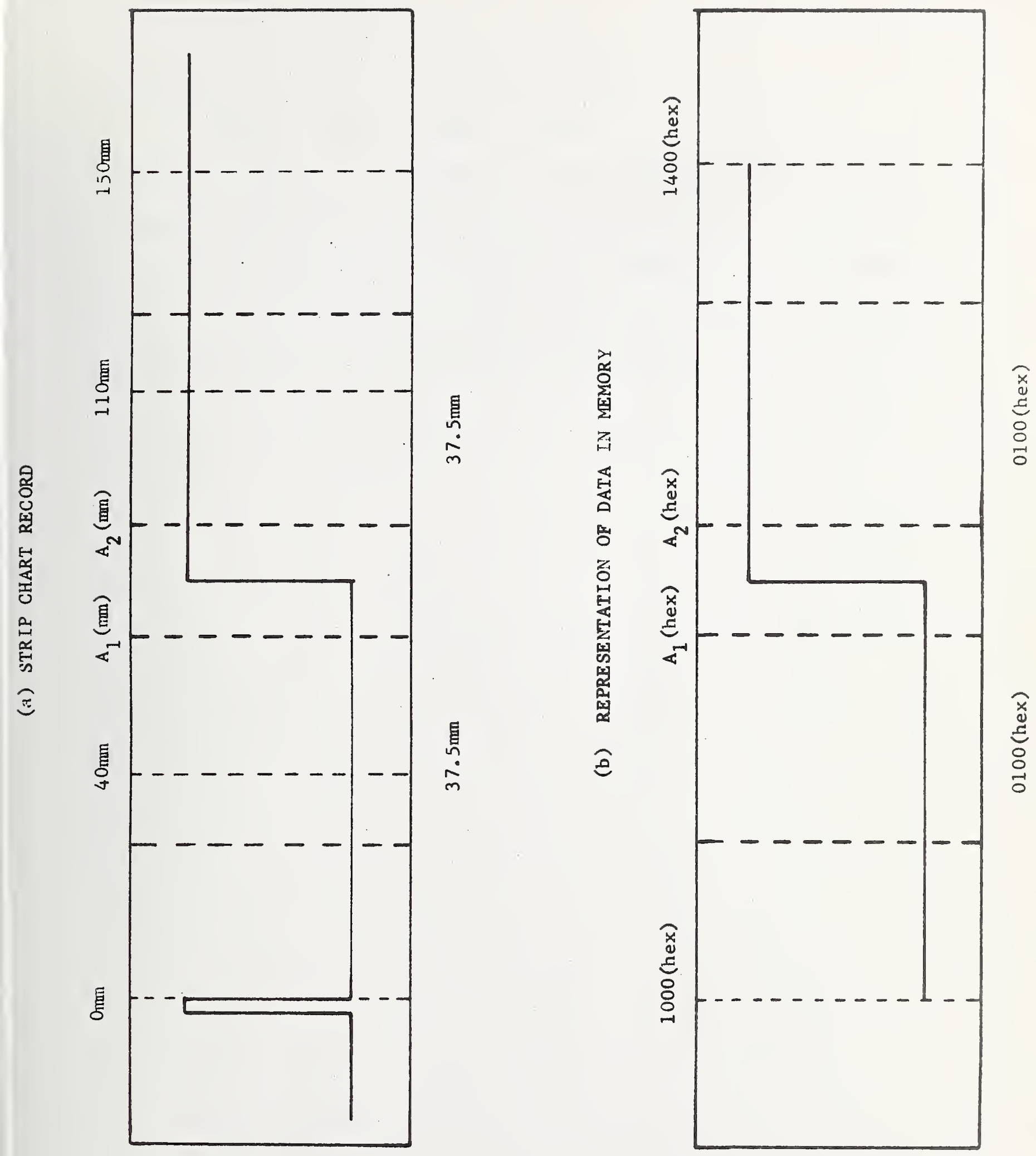

FIGURE 9 . SELECTION OF $A_{1}$ AND $A_{2}$ LOCATIONS 

and right of the step location, $S$, such that:

$$
S(m m)-A_{1}(m m)=A_{2}(m m)-S(m m) .
$$

$A_{1}$ and $A_{2}$ determine individually over which segment lines are to be computed; the mean of $A_{1}$ and $A_{2}$ determines the location at which a step is to be computed from the two lines. The effect on the calculation of the step height of proper (figure 10a) and improper (figure $10 b$ ) selection of $A_{1}$ and $A_{2}$ may be significant. 

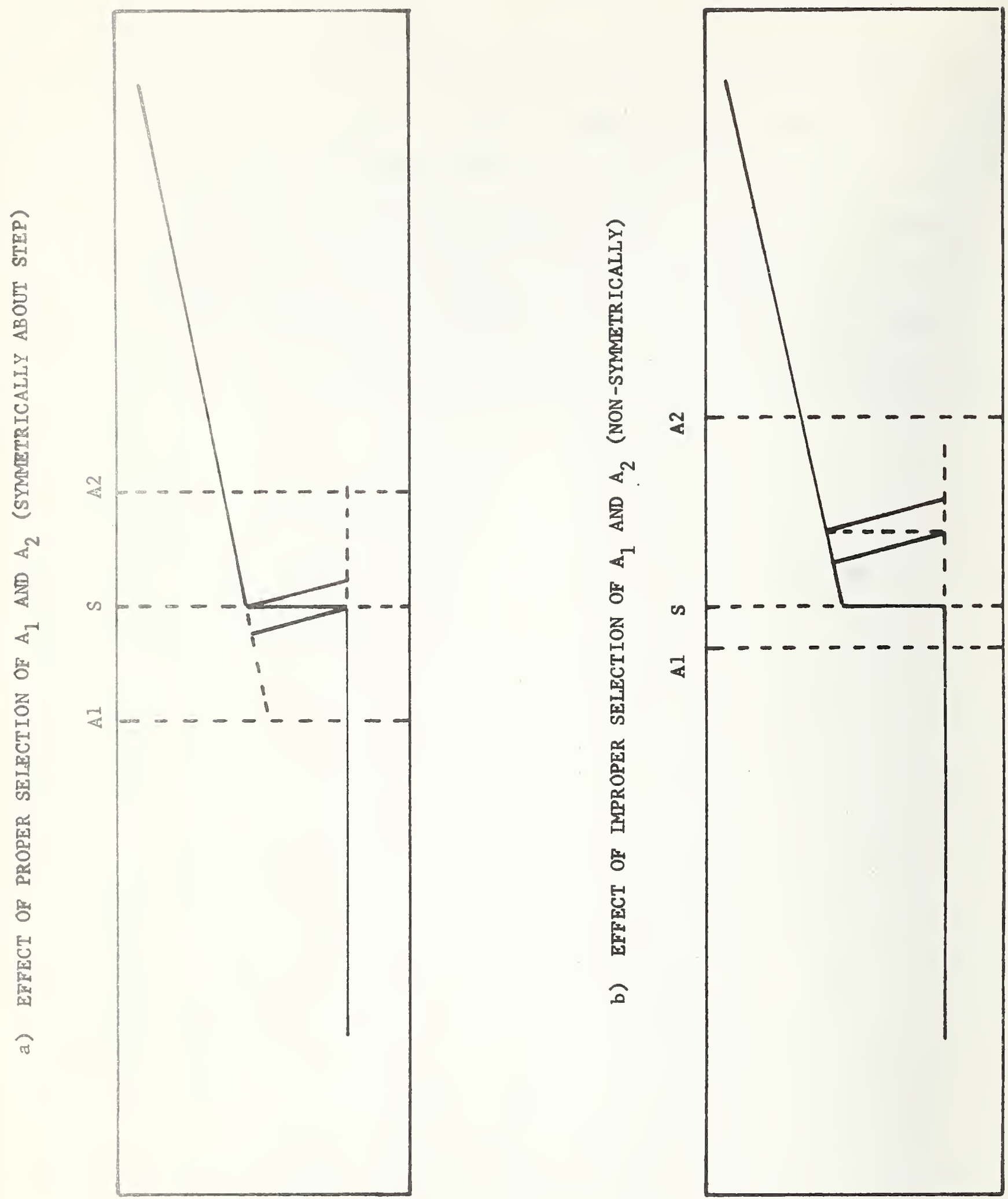

FIGURE 10. PROPER AND IMPROPER SELECTION OF $\mathrm{A}_{1}$ AND $\mathrm{A}_{2}$ 
The Mean Distance Between Two Non-Parallel Lines

The following vector analysis is employed to define the "mean perpendicular distance" between two non-parallel lines at some $\mathrm{x}$ coordinate $x m$. Line $L_{1}$ is defined by its slope, $a_{1}$, and the point $A_{1}$ with $x$ and $y$ coordinates $\left(0, b_{1}\right)$; line $L_{2}$ is similarly defined by $a_{2}$ and point $A_{2}$ at $\left(x, b_{2}\right)$ as in figure 11 . The general approach is to define vectors, $V_{1}$ and $V_{2}$, coincident with lines $L_{1}$ and $L_{2}$, respectively, and to find the perpendicular distances: $h_{1}$ from the point on $V_{1}$, with coordinate $x_{m}$, to $V_{2}$; and $h_{2}$ from the point on $V_{2}$, with coordinate $x_{m}$, to $V_{1}$. The mean distance, $h_{m}$, is then defined as the arithmetic average of $h_{1}$ and $h_{2}$.

The vector $V_{1}$ is defined as the difference between the vector to the general point $P_{1}$ and that to $A_{1}^{\prime}$ :

(1)

$$
\mathrm{V}_{1}=\mathrm{P}_{1}-\mathrm{A}_{1}^{\prime}
$$

$$
=\left[i\left(x_{1}\right)+j\left(a_{1} x_{1}+b_{1}\right)\right]-\left[i(0)+j\left(b_{1}\right)\right]
$$

(3) $=\left(i+a_{1} j\right) x_{1}$.

Similarly:

(4) $\quad V_{2}=P_{2}-A_{2}^{\prime}$ 

(5) $v_{2}=\left(i+a_{2} j\right) x_{2} \cdot$

The general vector between points $P_{2}$ and $P_{1}$ is:

(6)

$$
H=P_{1}-P_{2}
$$

(7)

$$
=i\left(x_{1}-x_{2}\right)+j\left(a_{1} x_{1}-a_{2} x_{2}+b_{1}-b_{2}^{\prime}\right) \text {. }
$$

To find the perpendicular distance from point $\mathrm{P}_{1}$ to the line $\mathrm{V}_{2}$, the product $\mathrm{H} \cdot \mathrm{V}_{1}$ is evaluated, set equal to zero, and the coordinate $x_{2}$ determined as a function of $x_{1}$.

Thus,

(8) $\mathrm{H} \cdot \mathrm{V}_{1}=\mathrm{x}_{1}\left(\mathrm{x}_{1}-\mathrm{x}_{2}\right)+\mathrm{a}_{1} \mathrm{x}_{1}\left(\mathrm{a}_{1} \mathrm{x}_{1}-\mathrm{a}_{2} \mathrm{x}_{2}+\mathrm{b}_{1}-\mathrm{b}_{2}^{\prime}\right)=0$

and

(9)

$$
x_{2}=\frac{x_{1}\left(1+a_{1}^{2}\right)+a_{1}\left(b_{1}-b_{2}^{\prime}\right)}{\left(1+a_{1} a_{2}\right)}
$$

The magnitude of the perpendicular distance, $\mathrm{H}_{1}$, is:

$$
\text { (10) } \mathrm{H}_{1}=\left[\left(\mathrm{x}_{1}-\mathrm{x}_{2}\right)^{2}+\left(\mathrm{a}_{1} \mathrm{x}_{1}-\mathrm{a}_{2} \mathrm{x}_{2}+\mathrm{b}_{1}-\mathrm{b}_{2}^{\prime}\right)^{2}\right]^{1 / 2} \text {. }
$$

Substitution of equation 9 into equation 10 yields:

$$
\text { (11) } \mathrm{H}_{1}=\left[\left(a_{1}-a_{2}\right) x_{1}+\left(b_{1}-b_{2}^{\prime}\right)\right]\left(1+a_{1}{ }^{2}\right)^{1 / 2}\left(1+a_{1} a_{2}\right)^{-1} \text {. }
$$


To find the perpendicular distance, $H_{2}$, from point $P_{2}$ to the line $\mathrm{V}_{1}$, the product $\mathrm{H} \cdot \mathrm{V}_{2}$ is evaluated similarly, with the result.

$$
\text { (12) } \mathrm{H}_{2}=\left[\left(\mathrm{a}_{1}-\mathrm{a}_{2}\right) \mathrm{x}_{2}+\left(\mathrm{b}_{1}-\mathrm{b}_{2}^{\prime}\right)\right]\left(1+\mathrm{a}_{2}{ }^{2}\right)^{1 / 2}\left(1+\mathrm{a}_{1} \mathrm{a}_{2}\right)^{-1} \text {. }
$$

Since $b_{2}^{\prime}=b_{2}-a_{2} x$ and $x_{1}$ and $x_{2}$ are chosen to be $x_{m}$, the distances $h_{1}$ and $h_{2}$ as indicated in figure 11 are given by:

(13) $h_{1}=\left[\left(a_{1}-a_{2}\right) x_{m}+\left(b_{1}-b_{2}+a_{2} x\right)\right]\left(1+a_{1}{ }^{2}\right)^{1 / 2}\left(1+a_{1} a_{2}\right)^{-1}$

and

$$
\text { (14) } h_{2}=\left[\left(a_{1}-a_{2}\right) x_{m}+\left(b_{1}-b_{2}+a_{2} x\right)\right]\left(1+a_{2}{ }^{2}\right)^{1 / 2}\left(1+a_{1} a_{2}\right)^{-1} \text {. }
$$

The mean perpendicular distance is then:

$$
h_{m}=1 / 2\left(h_{1}+h_{2}\right) .
$$




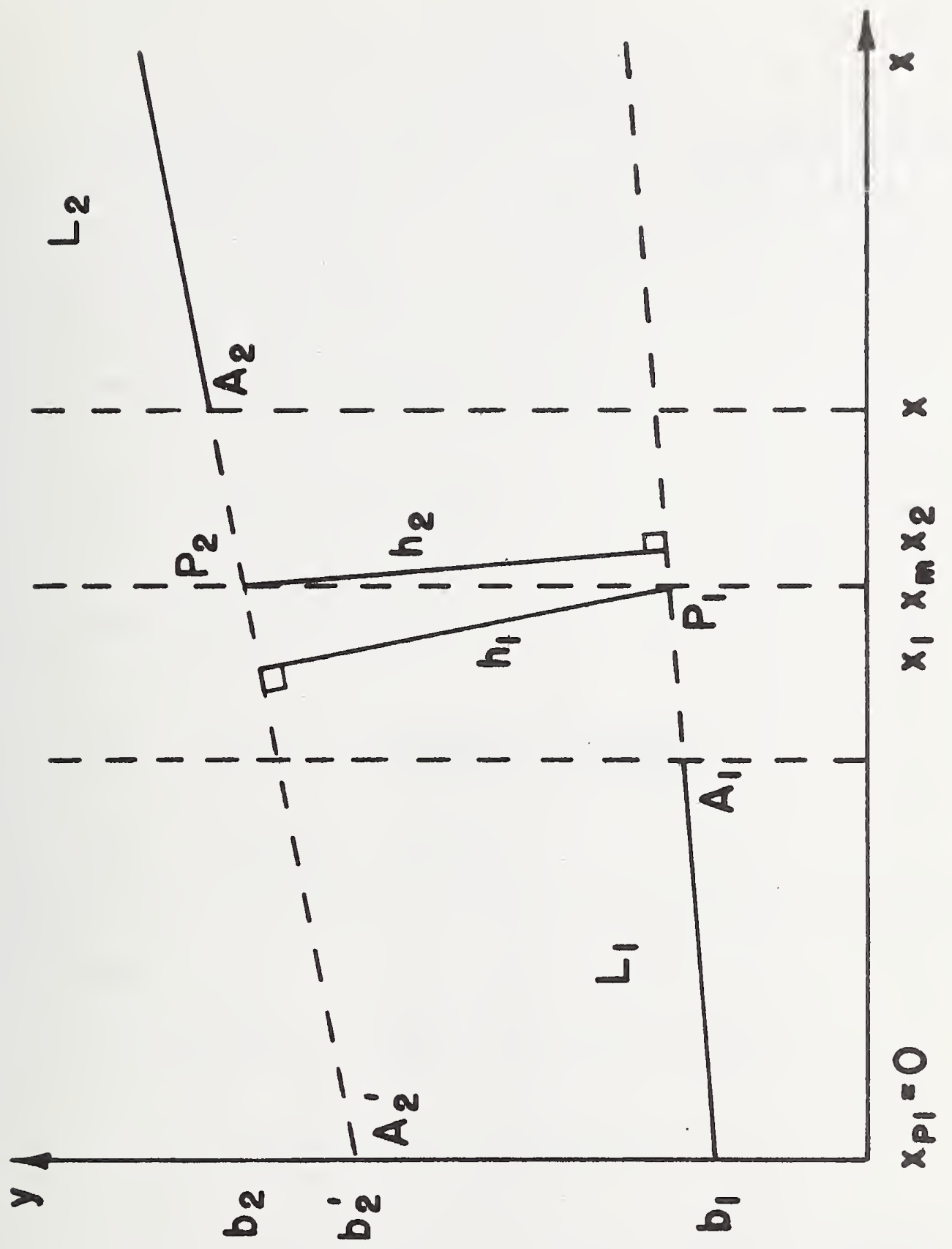

FIGURE 11 



\section{Appendix D \\ Slope Scale Factor}

Since the linear least squares curve fit utilizes single precision hexadecimal numbers as y coordinates and hexadecimal memory addresses as $\mathrm{x}$ coordinates, it is necessary to scale this coordinate system to that of the chart recorder.

The following transformation applies:

(1) $\quad y($ chart $)=k$ y(hex)

(2) $x($ chart $)=x($ hex $)$

The slopes are then related by:

(3) $\quad a($ char $t)=\frac{d y(\text { chart })}{d x(\text { chart })}=k \frac{d y(\text { hex })}{d x(\text { hex })}$

(4) $\quad a($ char $t)=k$ a (hex).

Substitution of equations 1,2 and 4 into equation 11 of appendix $C$ produces :

(5) $\mathrm{H}_{1}=\left[\left(\mathrm{ka}_{1}-\mathrm{ka}_{2}\right) \mathrm{x}_{1}+\left(\mathrm{kb}_{1}-\mathrm{kb}_{2}+\mathrm{ka_{1 }} \mathrm{x}\right)\right] \mathrm{x}$

$$
\begin{aligned}
& {\left[1+\left(k a_{1}\right)^{2}\right]^{1 / 2}\left[1+\left(k a_{1}\right)\left(k a_{2}\right)\right]^{-1}} \\
& =k\left[\left(a_{1}-a_{2}\right) x_{1}+\left(b_{1}-b_{2}+a_{1} x\right)\right]\left[1+\left(k a_{1}\right)^{2}\right]^{1 / 2}\left[1+k^{2} a_{1} a_{2}\right]^{-1} .
\end{aligned}
$$

Since similar equations apply to $\mathrm{H}_{1}$ and $\mathrm{H}_{2}$, the relationship between 
the two is independent of the leading multiplier and it may be omitted to give heights of the form:

(6) $\left.H_{1}=\left[\left(a_{1}-a_{2}\right) x_{1}+\left(b_{1}-b_{2}+a_{1} x\right)\right]\left[1+k a_{1}\right)^{2}\right]\left[1+\left(k a_{1}\right)\left(k a_{2}\right)\right]^{-1}$

Equation 3 may be evaluated using the full scale parameters of the chart and hexadecimal coordinate systems:

(5) $\quad 25.4 \mathrm{~mm} / 37.5 \mathrm{~mm}=\mathrm{k}\left(07 \mathrm{ff}_{16} / 0100_{16}\right)$

which yields in hexadecimal and decimal values:

(6) $k_{10}=0.08466$

(7) $\mathrm{k}_{16}=0.15 \mathrm{ACD}$. 


\section{Appendix E \\ Filter Characteristics}

The gain-bandpass characteristics of the filter circuits have been designed to conform with ANSI Standards when the device is used in conjunction with a Talysurf 4. The filter $3 \mathrm{db}$ down points are related to the conventional wavelength cut-offs through the stylus s peed :

$$
f(\mathrm{~Hz})=.06 \mathrm{in} / \mathrm{sec} \div \lambda_{c} \text { (in). }
$$

The filters are active Butterworths with selectable high-pass cut-off frequencies as indicated by figure 12. Roughness measurements are made with one of three high-pass filters in series with the single low-pass filter. Step height measurements are made with only the low-pass filter in the circuit.

The conformity of the filters to specified operation is indicated by the band pass curves in figure 12 and the observed phase delay in the low pass filter in figure 13. 


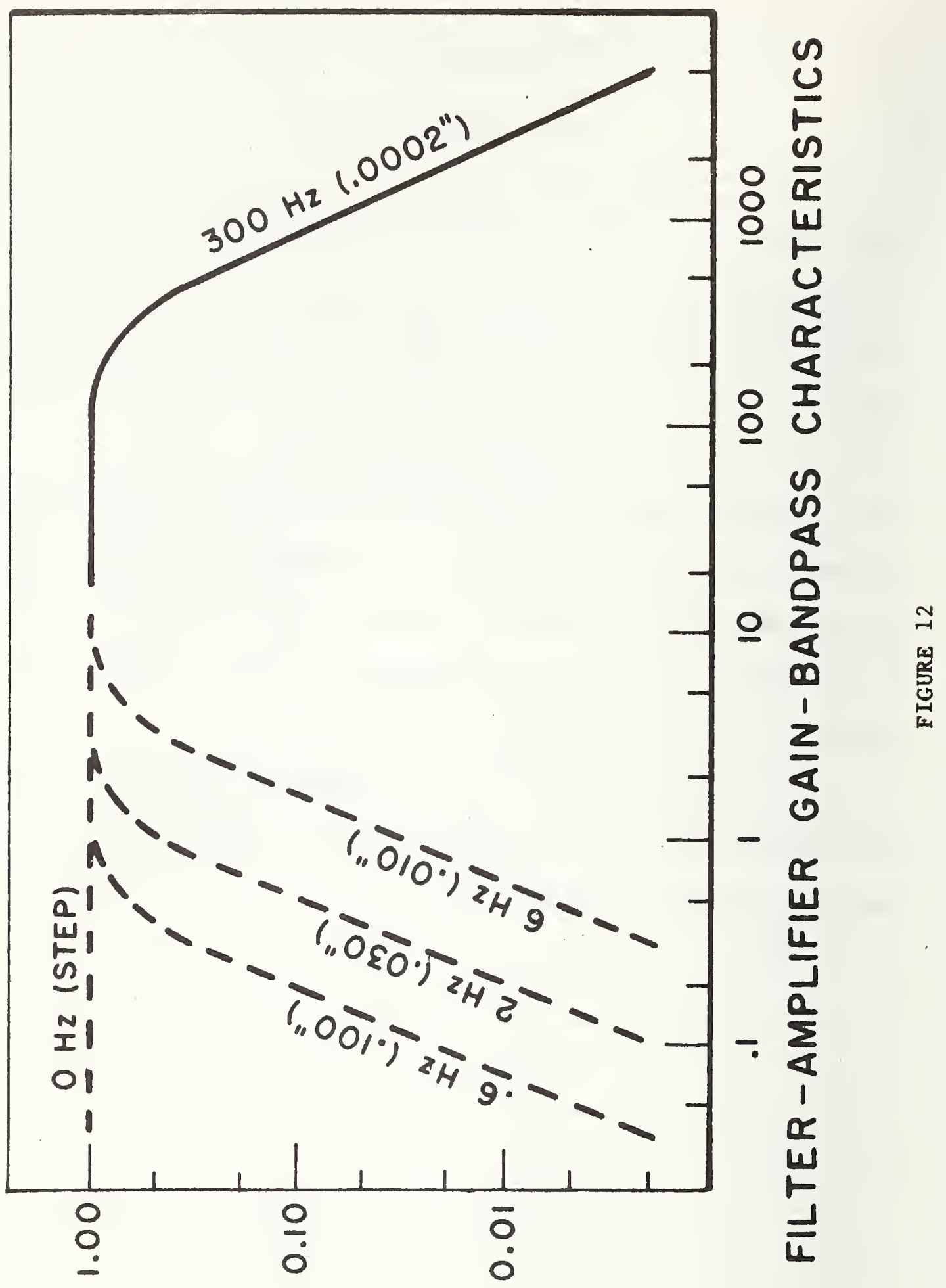




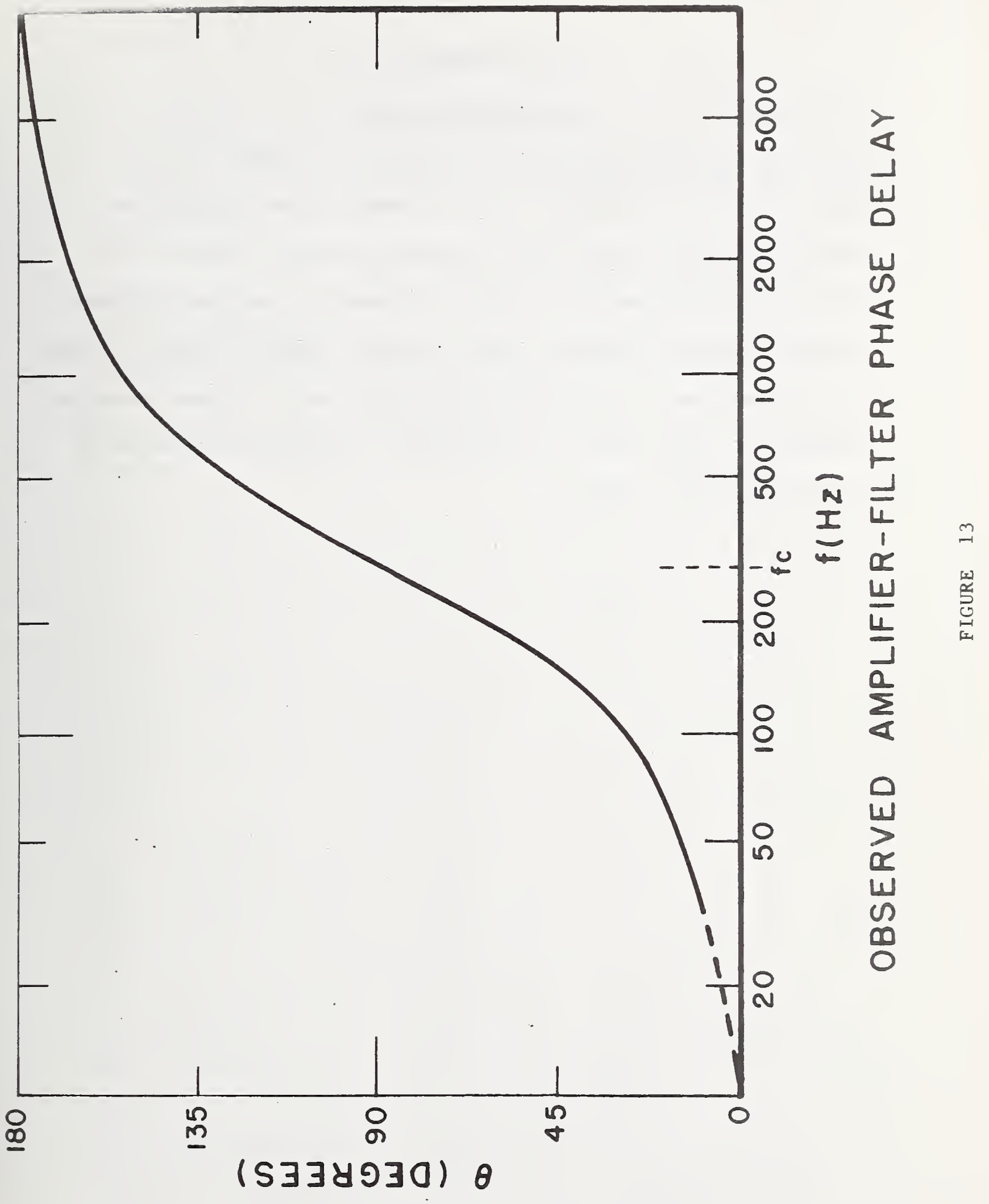




\section{Appendix F \\ Program Operation}

A flow-chart indicating the points in the program operation at which information is input at the A/D converter and Teletype and at which results are output at the eletype is shown in table 7 . In table 8 are shown numerical values of parameters involved in a sample program operation in which a fifty microinch calibration step is used in the measurement of an unknown step height and an unknown roughness specimen. A compilation of characteristic parameters of the entire system is given in table 9. 
TABLE 7

MASTLK PRO(IRAM LEVEL O

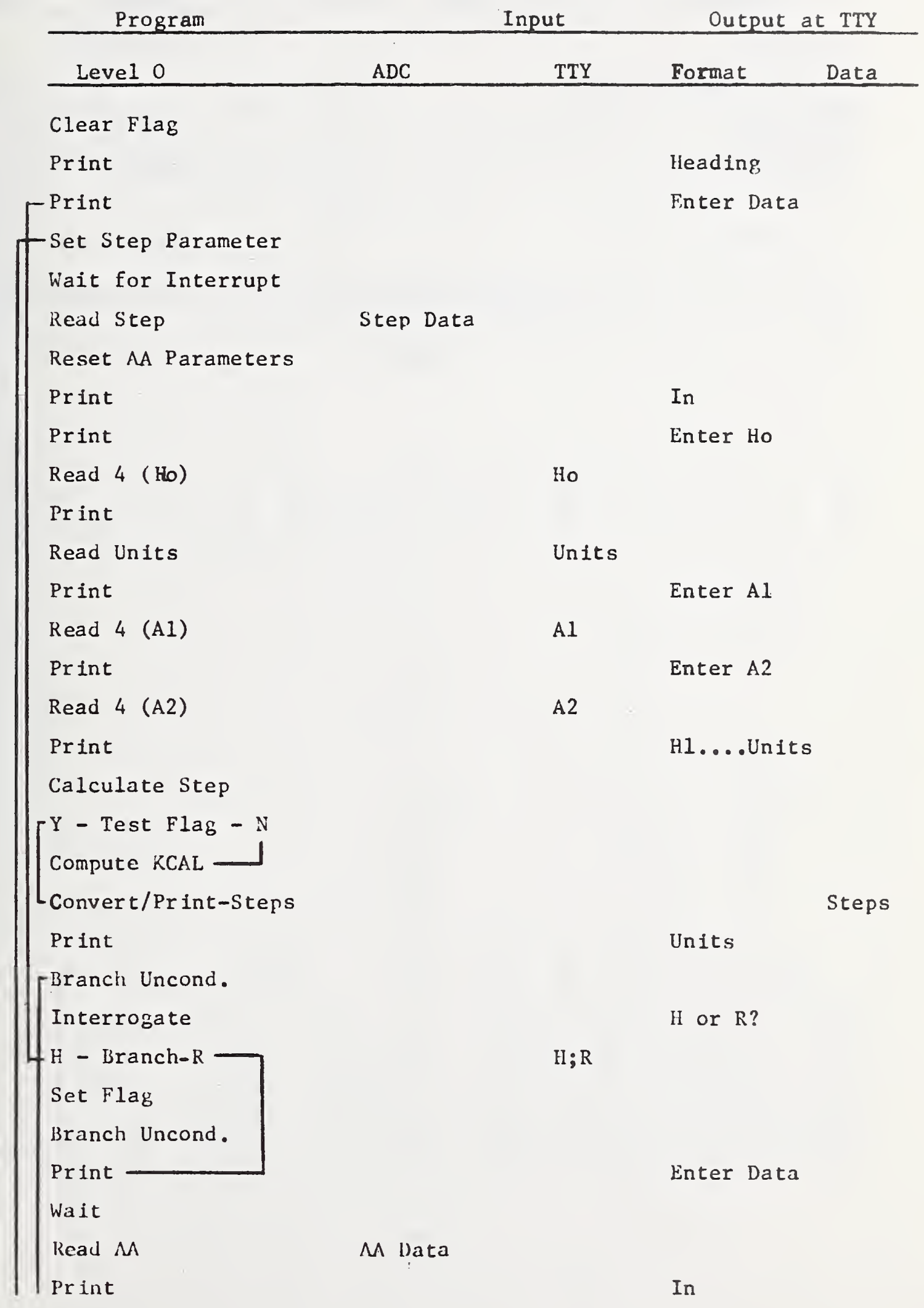


Table 7 cont.

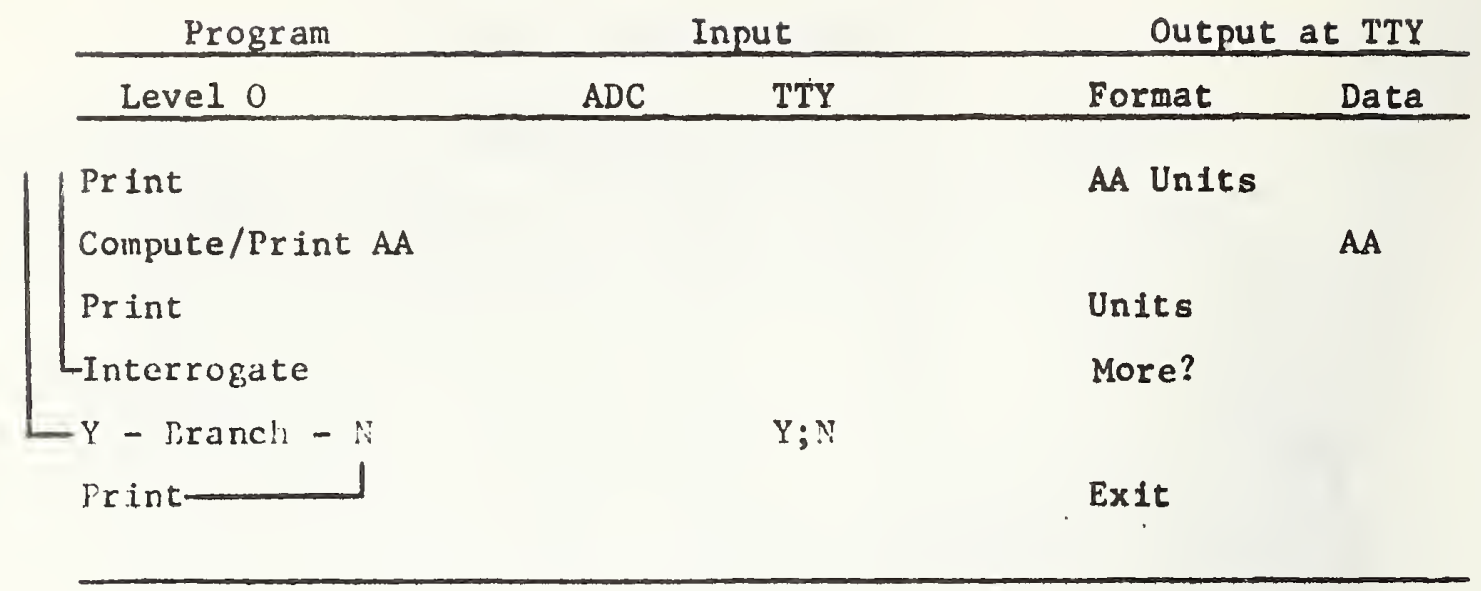

Table 7 


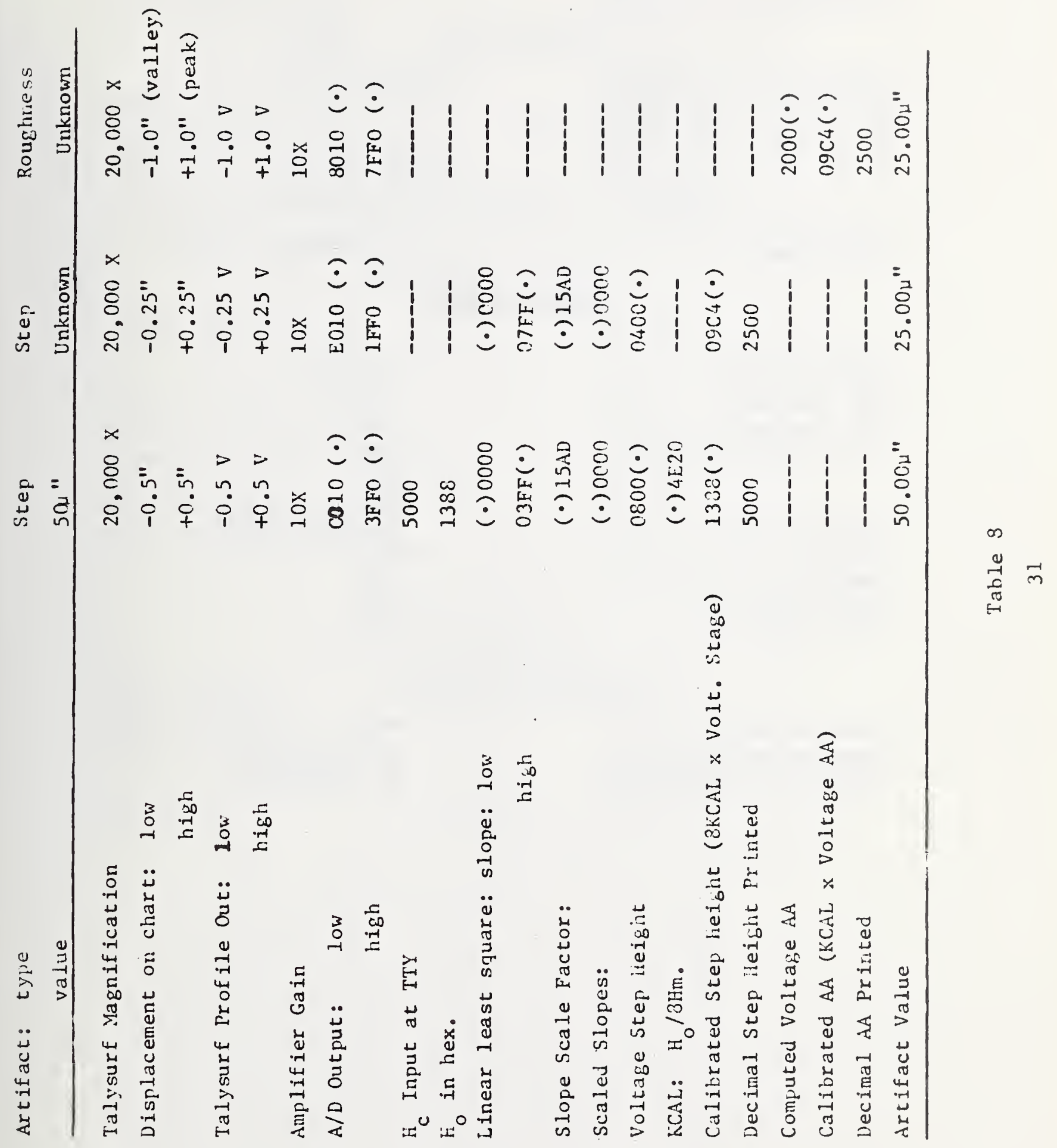


Table 9

Characteristic Parameters

Talysurf 4

Profile Uutput (nominal)

Relay Output (nominal)

Magnification (vertica], max.)

$\pm 1 \mathrm{~V}$
$-4 \mathrm{~V}$

$10^{5}$

Stylus speed $(4 X)$

$3.6^{\prime \prime} / \mathrm{min}$.

$(20 x)$

$(100 x)$

$0.72^{\prime \prime} / \mathrm{min}$.

$0.14^{\prime \prime} / \mathrm{min}$.

$.150^{\prime \prime}$

Scan Distance (.030" cutoff, 4X)

$14.4^{\prime \prime} / \mathrm{min}$.

Chart Speed

Filter-Amplifier

Input (11mited)

Input Impedance

Gain (nominal)

$\overline{1} 00 \mathrm{k} \Omega$

itigh Frequency cut-of $f$

$10 \mathrm{X}$

Low Frequency cut-off

$300 \mathrm{HL}$

$6 \mathrm{HZ}$

$2 \mathrm{HZ}$

$.6 \mathrm{~Hz}$

Filter Roll-off

Flatness

$-12 \mathrm{db} /$ octave

Overall Linearity

Output (nominal)

Noise Output

$+.02 \mathrm{db}$

$.02 \%$

$+10 \mathrm{~V}$

<5 mv.

Interface Circuitry

Inverter Output

$+4 \mathrm{~V}$

Event Marker Output

Interrupt Signal output

$+1.35 \mathrm{~V}$ (1 sec.)

$\overline{3 V}(50 \mu \mathrm{sec})$ 
Data Input: Step Mode

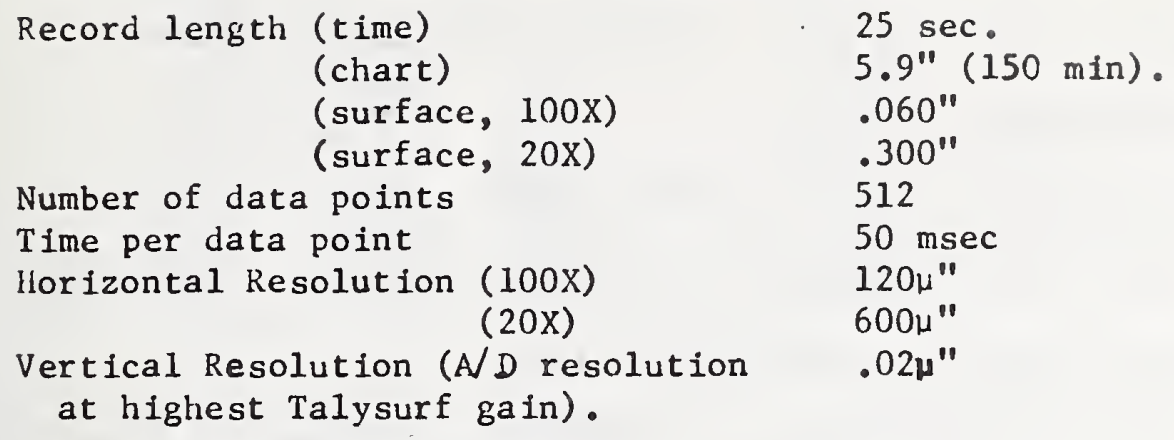

\section{Data Input: AA Mode}

Record length (time)

(chart)

(surface, $4 X$ )

Number of data points

Time per data point

lorizontal resolution (4Y)

Vertical resolution (at $10^{5} \mathrm{X}$ )

Short Wavelength cut-off

Long wavelength cut-off
$2.5 \mathrm{sec}$

$.6^{\prime \prime}$

$.150^{\prime \prime}$

4096

$600 \mu \mathrm{sec}$

$37 \mu "$

$.005 \mu "$

$200 \mu^{\prime \prime}$

$.010^{\prime \prime}$

$.030^{\prime \prime}$

$.100^{\prime \prime}$

\section{A/D Converter}

Input Voltage

Input Impedance

Output (including sign)

Resolution (voltage)

(relative)

Linearity
$+10 \mathrm{~V}$

$\overline{10} 0 \mathrm{M} \Omega$

$12 \mathrm{bit}$

$5 \mathrm{mv}$

$.025 \%$ FS

$.010 \%$ FS 


\section{Append Ix G \\ Operator's Instructions: Interdata $3 /$ Talysurf 4 system}

\section{Preliminary Set-up}

A. Instrumentation: the following connections are necessary:

1. those on the Talysurf for normal operation as indicated by the Talysurf Operating Instructions manual;

2. those internal to the $A / D$ converter as shown in figure 14;

3. the power cord of the interface electronics as in figure 15 (N.B. Disconnect main power line to computer when connecting this line).

4. The external leads between the Talysurf, interface electronics and $A / D$ converter as in figure 16.

B. Software: the following programs must reside in memory:

1. the hexadecimal monitor $(3 A 80-3 F F F)$;

2. the arithmetic subroutines (3010-35FF);

3. the master program (0080-1000).

\section{General System Operation}

A. Calibration of Stylus Instrument

\section{Magnification Selection}

(a) Align unknown specimen on Talysurf;

(b) traverse stylus with chart recorder on and select magnification on Talysurf electronic unit to obtain approximately three-quarters of maximum on-scale deflection of recorder pen;

(c) turn off recorder and select calibration step 


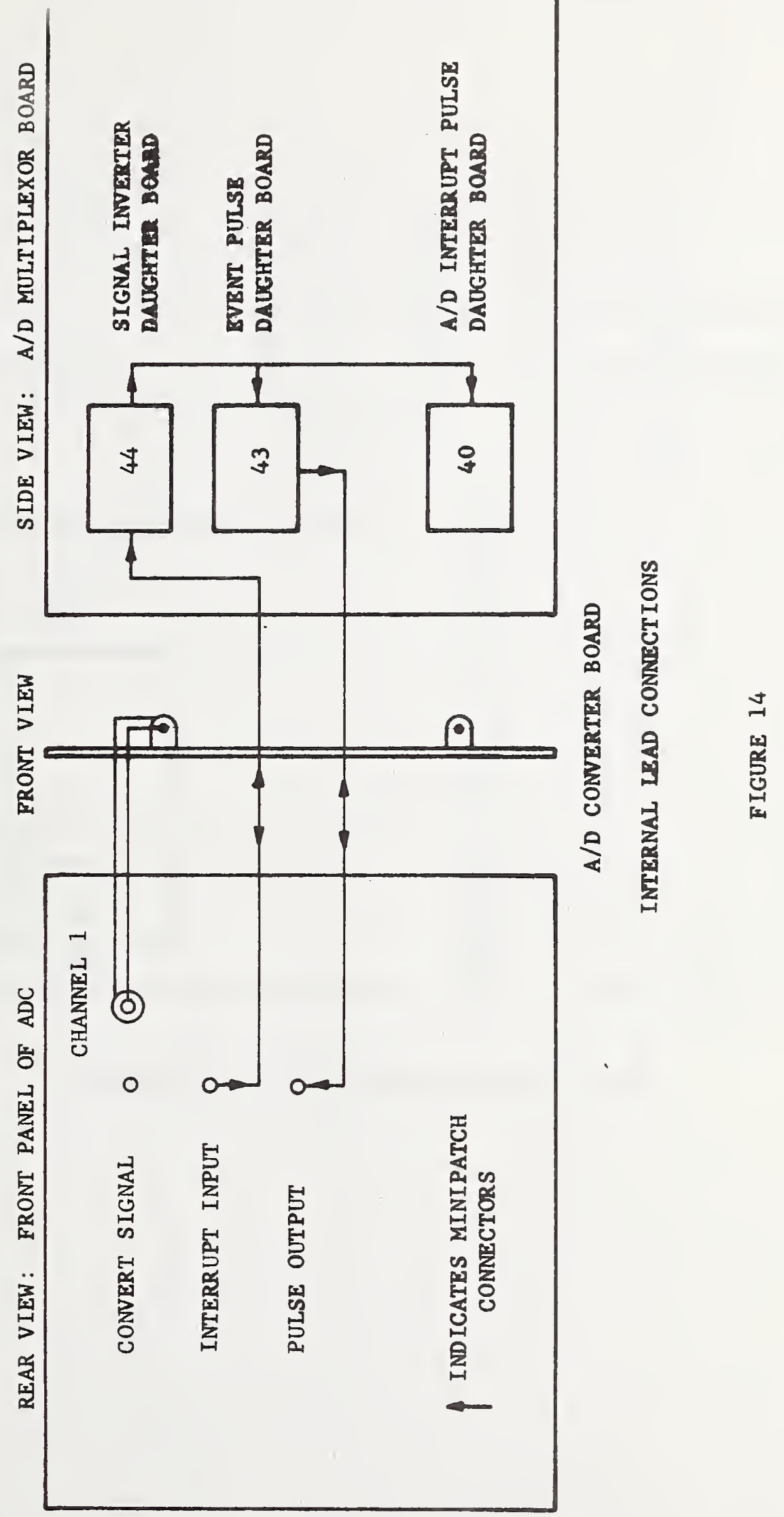




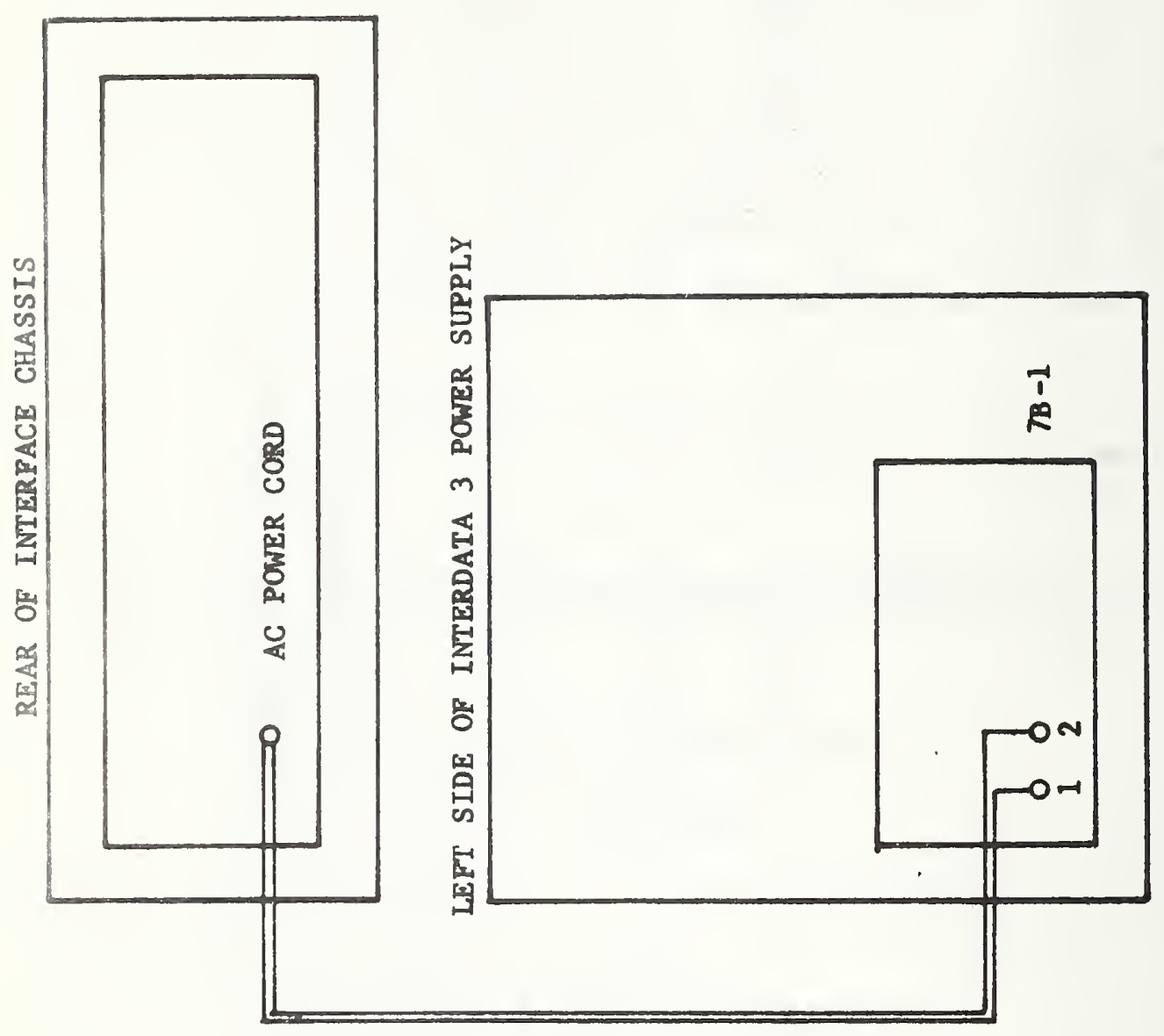

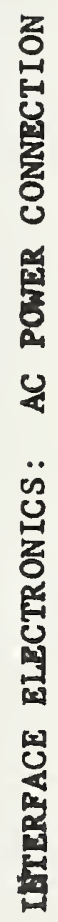




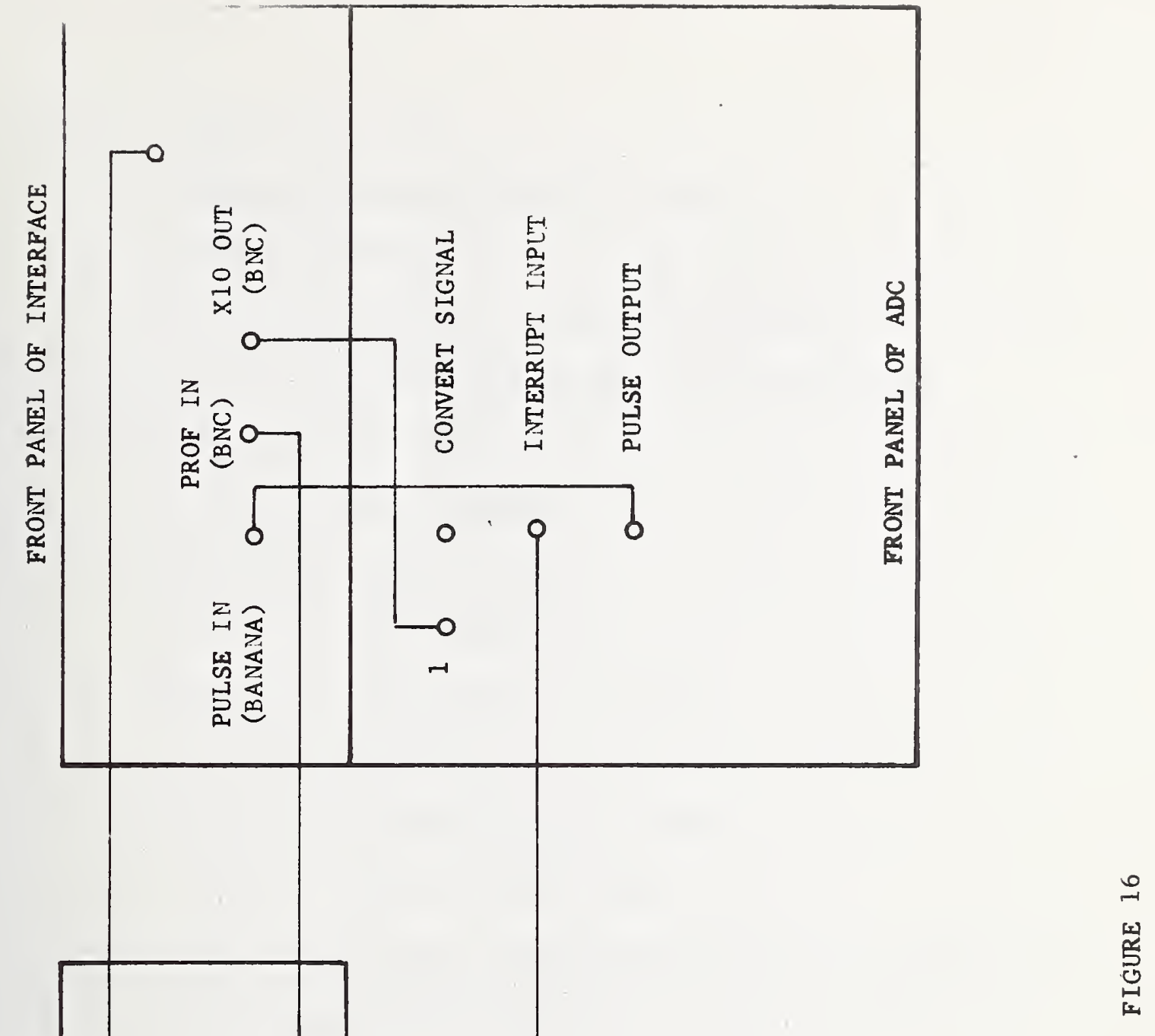


artifact of appropriate size.

2. Input of Calibration Step: Set-up

(a) Set switches

(1) Talysurf Electronic Control Unit

(1) Magnification: as determined in

(2) Cut-off: K

(3) Operation: $\mathrm{N}$

(2) Talysurf Gear Box

(1) Stroke knob: L

(2) Speed knob: $\times 20$

(3) Interface Electronics

(1) Mode Select: 10X

(2) Cut -off: Step

(b) Align artifact and traverse stylus to obtain trace with step edge in proper position relative to the event mark (see appendix B).

(c) Rotate the Talysurf Setting Lever at the left (CCN) position (see p. 4 of Talysurf Manual and Note 1 below).

3. Input of Calibration Step: Program Execution

(a) Begin program executive from TTY Control (OEOOG)

(b) At "enter data": turn on the chart recorder and gently move the Setting Lever to the right (OW); data will be read for twenty-five seconds.

(c) At In: shut off the chart recorder and tear off the recorded trace; 
(d) A1 and A2 selection:

(1) with the "Step Locator Scale", determine the position in $\mathrm{mm}$ of the step edge relative to the trailing edge of the event mark (see appendix B);

(2) select A1 and A2 symmetrically about the step edge.

(3) Decord on the strip chart the $\mathrm{mm}$ and address loca-

tions of $\mathrm{Al}$ and $\mathrm{A2}$;

(e) At "Enter HO": type in the step height value as four digits and depress the space bar on the TTY;

(f) At "Enter Units": type in a two character unit symbol (do not press the space bar);

(g) At "Enter A1"; type in the four-digit address A1 and depress the space bar;

(h) at "Enter A2"; either A2 as above; the computer will now print out the computed step heights $\mathrm{H} 1, \mathrm{H} 2$ and $\mathrm{HM}$ with units.

\section{(i) At "More?":}

(1) If the computed step heights are unsatisfactory, type $\mathrm{N}$ and repeat the procedure from step 3a;

(2) If the heights are satisfactory, type $Y$.

B. Calibration of Unknown Specimen

1. Align the specimen on the Talysurf and traverse the stylus to obtain a properly centered trace.

2. Calibration of a Step

(a) Repeat procedure in IIA2, b and c; 
(b) At "H or R?": type in $\mathrm{H}$;

(c) At "Enter Data", follow procedure from IIA3, b thru h;

3. Calibration of a Roughness

(a) Select filter cut-off on interface; select X4 stroke speed on Talysurf; type R.

(b) At "Enter Data", rotate the Setting Lever to right position (CW); data will be read for 3.5 seconds.

(c) The computed AA and units will now be printed.

4. At "More?" :

(a) If a step is to be calibrated, type $\mathrm{Y}$; then at

"H or R?", type $\mathrm{H}$.

(b) If a roughness is to be calibrated, type $Y$, then at "H or $\mathrm{R}$ ?", type $\mathrm{R}$.

(c) If no more measurements are to be made, exit from program by typing $\mathrm{N}$.

Note 1. The Event Marker appears on the chart recorder at the "Start of cut-off average" position in the stroke. With the stroke knob on the gear box at position $L$, the event mark appears when the marks on the gear box window are aligned as indicated below. Therefore, in returning the setting Lever to the left (CCW) position, it is necessary only for $L$ mark to be to the left of the rightmost mark on the upper scale. 
Appendix H

\section{Checklist for Proper Electrical Operation}

\section{Talysurf Outputs}

(1) The profile Output should produce a voltage of nominally +1 volt when the pen is at the 2 inch mark on the strip chart and -1 volt at the zero inch mark.

(2) The relay output should be a negative - going step of four volts at the "Start of cut-off average" position of the stylus stroke (see Talysurf Manua1).

A/D Outputs

(1) With the Talysurf relay output connected to the Interrupt Input terminal on the $A / D$ converter front panel, the $A / D$ output at the Pulse Output terminal should be a zero to volts pulse of about one second duration; (simultaneously the computer interrupt should trigger internally).

\section{Interface Electronics Outputs}

(1) With the system fully wired (figure 16), the output at the X10 OUT should be the amplified, filtered Profile Out Signal;

(2) A one-second pulse of nominally one volt should be present at the "PROFILE IN" terminal (and a similar one recorded on the chart recorder) at the "Start of cut-off average" stroke position. Internal A/D Signals (A/D Multiplex or Board).

With the Talysurf relay signal at the Interrupt Input: 
(1) the output of the signal inverter (daughter board 44) should be a positive-going step of four volts;

(2) the output of the A/D Interrupt pulse (daughter board 40) should be a 50 microsecond positive-going pulse of about four volts. 



\begin{tabular}{|c|c|c|}
\hline $\begin{array}{l}\text { NBSIR 73-106 } \\
\end{array}$ & $\begin{array}{l}\text { 2. Gov't Accession } \\
\text { No. }\end{array}$ & 3. Recipient's Accession No. \\
\hline \multicolumn{2}{|l|}{ 4. TITLE AND SUBTITLE } & 5. Publication Date \\
\hline \multicolumn{2}{|c|}{ A SYSTEM FOR COMPUTERIZED SURFACE ROUGHNESS MEASUREMENT } & 6. Performing Organization Code \\
\hline \multicolumn{2}{|l|}{$\begin{array}{l}\text { 7. AUTHOR(S) } \\
\text { Dennis A. Swyt }\end{array}$} & $\begin{array}{l}\text { 8. Performing Organization } \\
\text { NBSIR 73-106 }\end{array}$ \\
\hline \multicolumn{2}{|l|}{ 9. PERFORMING ORGANIZATION NAME AND ADDRESS } & 10. Project/Task/Work Unit No. \\
\hline \multicolumn{2}{|l|}{$\begin{array}{l}\text { NAT IONAL BUREAU OF STANDARDS } \\
\text { DEP ARTMENT OF COMMERCE } \\
\text { WASHINGTON, D.C. } 20234\end{array}$} & 11. Contract/Grant No. \\
\hline \multicolumn{2}{|l|}{ 12. Sponsoring Organization Name and Address } & $\begin{array}{l}\text { 13. Type of Report \& Period } \\
\text { Covered }\end{array}$ \\
\hline \multicolumn{2}{|l|}{ - } & 14. Sponsoring Agency Code \\
\hline
\end{tabular}

15. SUPPLEMENTARY NOTES

16. ABSTRACT (A 200-word or less factual summary of most significant information. If document includes a signific ant bibliography or literature survey, mention it here.)

An overall system for computerized surface roughness measurements, involving a commercial stylus profile instrument and a minicomputer, is described. The method allows: direct displacement calibration of the stylus instrument by means of interferometrically measured gage block steps; the elimination of roughness artifacts as calibration standards; and access to punched-tape surface profile data which may be given detailed analysis on a la rger, faster computer. Details of system operation and precision are included.

17. KEY WORDS (Alphabetical order, separated by semicolons) Surface profile instrumentation; surface roughness calibrations; surface roughness measurement.

18. AVAILABILITY STATEMENT

UNLIMIT ED.

$x$ FOR OFFICIAL DISTRIBUTION. DO NOT RELEASE TO NTIS.

19. SECURITY CLASS
(THIS REPORT)
UNCL ASSIFIED
20. SECURITY CLASS
(THIS PAGE)
UNCL ASSIFIED

21. NO. OF PAGES

22. Price 



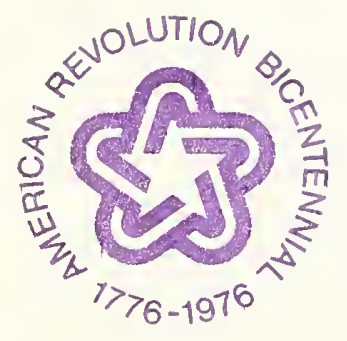

